\title{
Contributions of water-rock interactions to the composition of groundwater in areas with a sizeable anthropogenic input: A case study of the waters of the Fundão area, central Portugal
}

\author{
Fernando Pacheco \\ Seç̧ão de Geologia, Universidade de Trás-os-Montes e Alto Douro, Vila Real, Portugal \\ Cornelis H. van der Weijden \\ Department of Geochemistry, Institute of Earth Sciences, Utrecht University, Utrecht, Netherlands
}

\begin{abstract}
We used a combination of a grouping algorithm and a weathering algorithm to assess the contributions made by chemical weathering and anthropogenic inputs to the groundwater composition in a granitoid area. The first algorithm is based on the mathematical concept of equivalent relations between objects and is used to find groups of water samples. Using the grouping algorithm, we identified groups with similar chemistries in a set of data relating to the water composition in 160 springs and wells in the Fundão area (Portugal). The second algorithm is based on stoichiometries, mass, and charge balances in weathering reactions and is used to relate the water composition of each identified group to water-mineral interactions in the area. Background information on the petrology and mineralogy of the area allowed us to choose the most realistic watermineral interactions. We also had information about the use and composition of fertilizers in this agricultural area. In applying the weathering algorithm we considered all dissolved silica and bicarbonate to be produced by chemical weathering and all dissolved chloride, sulphate, and nitrate to be derived from other sources, mainly from fertilizers. The anthropogenic contributions to the water chemistries in the area are high. Despite the high background concentrations derived from pollution, we were able to assess the contribution of weathering to the water chemistries. We obtained realistic results with the two algorithms, supported by the fact that the spatial distribution of the samples belonging to the various groups shows a good correlation with the geology and petrology of the area.
\end{abstract}

\section{Introduction}

The composition of natural waters is determined by a number of processes, which include wet and dry deposition of atmospheric salts, evapotranspiration, and water-soil and water-rock interactions. Garrels and Mackenzie [1967] presented a classical analysis of the natural processes responsible for the composition of springs and groundwater in a pristine area. First, they corrected the water composition for atmospheric input and then, step by step, they used the cations, anions, and dissolved silica to reconstruct the primary minerals from their secondary weathering products until all dissolved components had been used. From the stoichiometry of these reverse weathering reactions they estimated the mass of the primary minerals involved in the water-rock interactions. Quite a number of studies on the relation between groundwater composition and water-rock interaction have been carried out since then. We refer to work published by Garrels [1967], Tardy [1971], Tardy et al. [1973], Pačes [1971, 1973], Drever [1988], Sverdrup and Warfvinge [1991], and Velbel [1985a, b, 1989, 1992] and references therein. These studies were carried out in areas with a minimum anthropogenic input. Such areas are Copyright 1996 by the American Geophysical Union.

Paper number 96WR01683.

0043-1397/96/96WR-01683\$09.00 becoming increasingly scarce, and in many areas the groundwater contains a considerable amount of chemicals derived from human activities.

In inhabited areas, especially where there is intensive agriculture and/or industry, the water composition is usually affected by fertilization and manuring, by leachates of solid waste, and by domestic and industrial effluents. In general, there is no easy way to distinguish between the contributions made by natural sources and those made by anthropogenic sources. The only components that in all likelihood, are solely or at least predominantly derived from water-rock interactions are silica and bicarbonate. In this paper we will discuss the results of a method that combines a mathematical algorithm (based on the concept of equivalent relations) that can identify groups in a set of groundwater analyses and a weathering algorithm that relates the group medians to water-mineral interactions. The water samples were collected in the Fundão area (Portugal), situated in a granitoid complex intersected by a number of aplites and basic dikes.

\section{The Fundão Area}

The Fundão area (Figures 1a and $1 b$ ) is situated in the province of Beira Baixa (central Portugal). The area is located at the confluence of the Zêzere and Meimoa rivers. The lowest part of the area lies about $400 \mathrm{~m}$ above sea level. The Serra da 


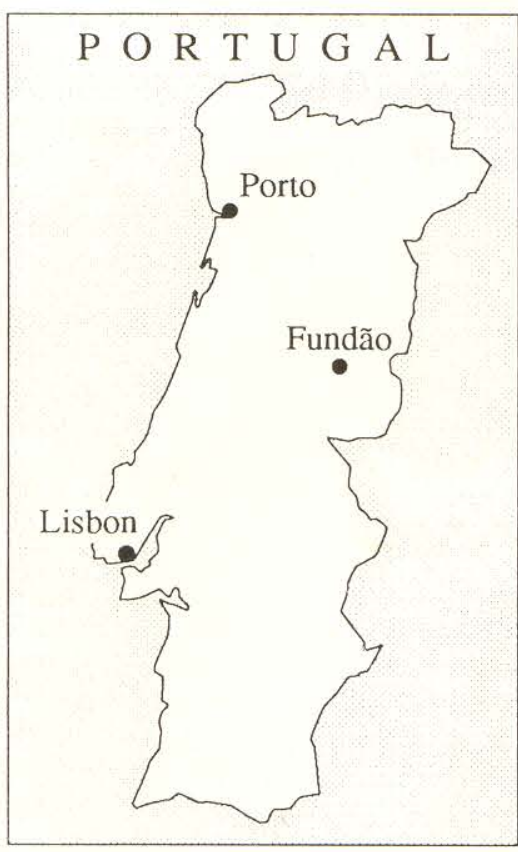

Figure 1a. Geographical map of Portugal indicating the position of the Fundão area.

Gardunha, bordering the area in the south, has peaks between 1200 and $1300 \mathrm{~m}$ above sea level. Hills bordering the area to the east and west have altitudes of between 500 and $600 \mathrm{~m}$. This leads to a general drainage pattern in the NW direction, but the drainage pattern is also controlled by the SSW-NNE direction of faults in this region. The streamlets are intersected by the Rio da Meimoa, which crosses the area from east to west just south of Alcaria. The streamlets from the Serra da Gardunha are perennial, but upon reaching the valley most of their water disappears into the weathered granitoid subsoil. During summer, water is transported mainly through streambed gravels.

The groundwater flow in the area depends on the topography of the contact between fresh and weathered rocks. The system of joints does not have a large storage capacity. The area, more specifically the southern part, has many springs, most of them perennial. Many wells have been dug in the area, mainly in the valley. The wells that are close to the streambeds give large yields, but farther from the beds the yields are small (a few cubic meters per day).

The climate is very good for agriculture; this is concentrated in the southern part, where there is a plentiful water supply. The poor granitic soil has to be fertilized. Besides the nutrients nitrate, ammonium, phosphate, and potassium, the locally applied fertilizers also contain high amounts of calcium, chloride, and sulphate and minor amounts of sodium. Fertilizers high in magnesium are also frequently applied in apple and cherry orchards in the area. The fertilization has a large impact on the water chemistry. As a first-order working hypothesis, we assume that the application of fertilizers has resulted in a steady state occupancy of exchange sites by the major cations. The atmospheric input of carbonate particles is negligible and liming of the soils in the area is only sporadic. Therefore one is justified in assuming that all bicarbonate is derived from waterrock interaction.

\section{Petrology and Mineralogy}

\section{Petrology}

The Fundão plutonite has an exposed area of approximately $100 \mathrm{~km}^{2}$. The main lithological types present (Figure 2a) are tonalites, although some granites and monzonitic granites appear in places. These units are cut by two dominant types of

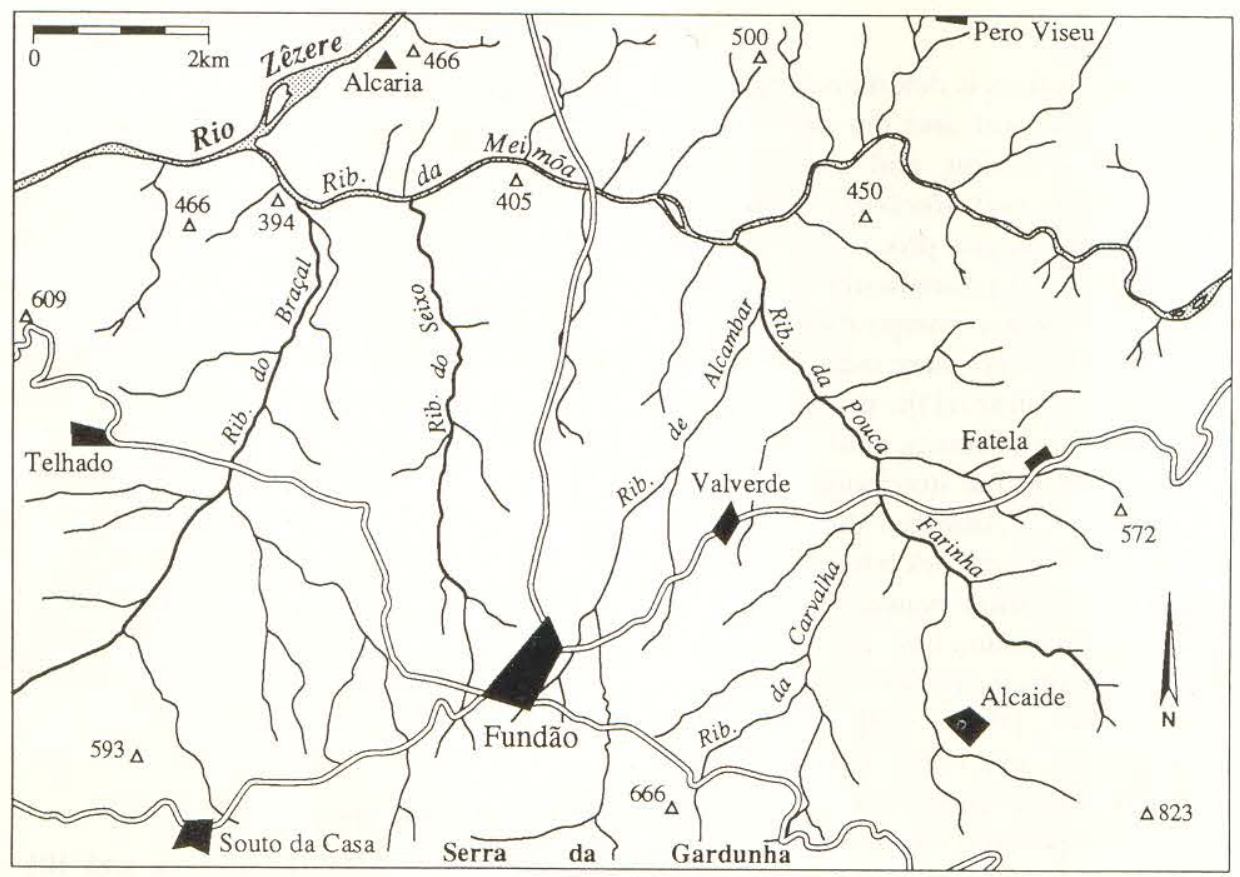

Figure 1b. Blow-up of the Fundão area with the major villages (black polygons) and connecting roads (double lines), the rivers Zèzere and Meimoa and their tributary streams and streamlets, topographical heights (triangles with altitudes in meters above sea level), and the position of the Serra da Gardunha. 


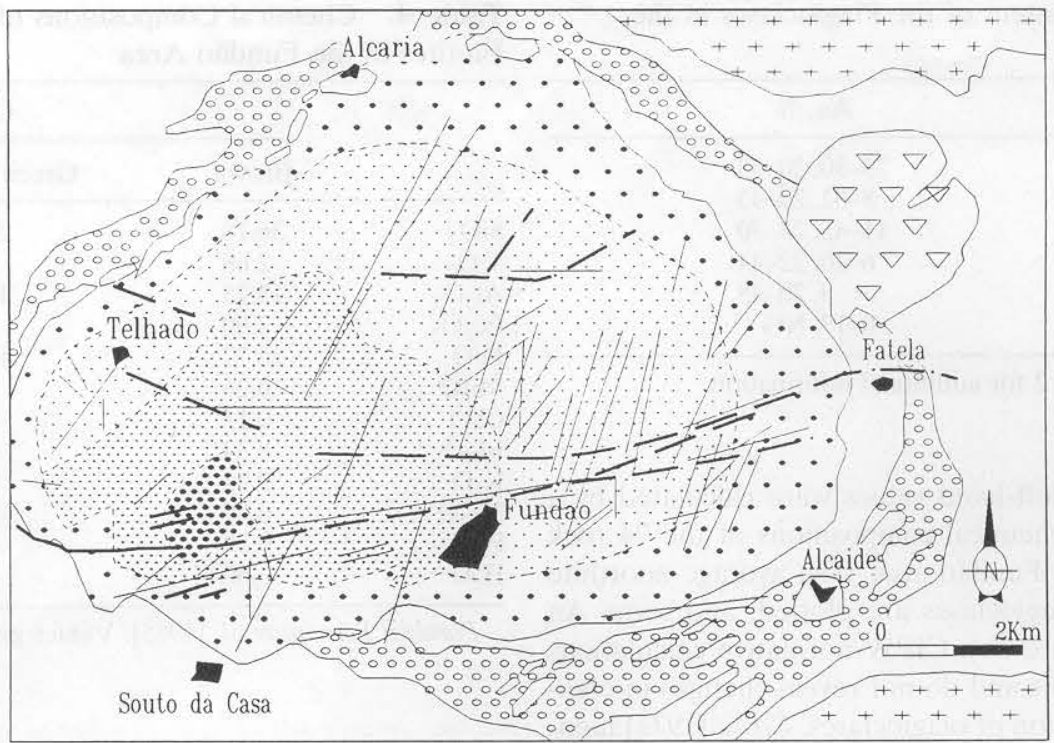

Legend:
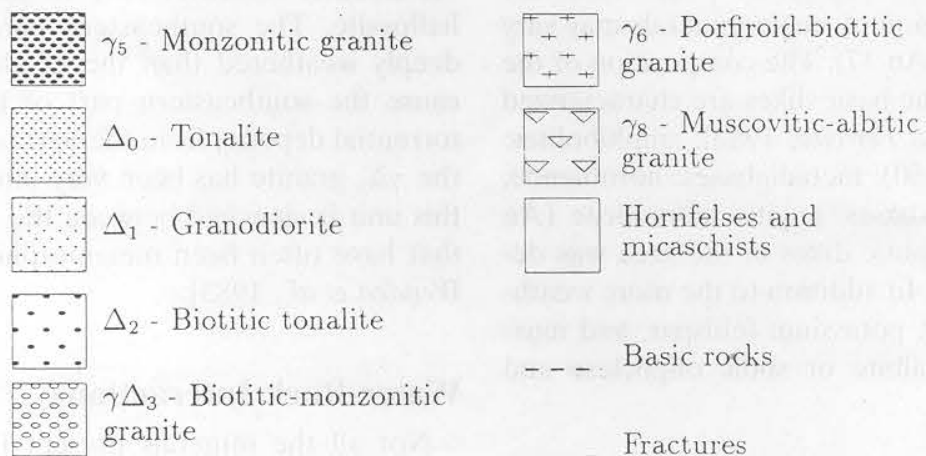

Figure 2a. Geological map of the Fundão area (simplified and modified after Portugal Ferreira et al. [1985]).

structures: (1) EW alignments, consisting in a dike swarm of basic and in some cases aplitic rocks, and (2) N35E faults, filled with breccias and showing strong evidence of hydrothermal alterations [Portugal Ferreira et al., 1985]. The chemical com-

Table 1. Average Chemical Compositions of the Petrographical Units in the Fundão Area Shown in Figure $2 \mathrm{a}$

\begin{tabular}{lcccccc}
\hline & $\Delta_{0}$ & $\Delta_{1}$ & $\Delta_{2}$ & $\gamma \Delta_{3}$ & $\gamma_{5}$ & $\gamma_{8}$ \\
\hline $\mathrm{SiO}_{2}$ & 67.0 & 65.2 & 65.1 & 70.4 & 75.9 & 73.0 \\
$\mathrm{TiO}_{2}$ & 0.51 & 0.58 & 0.52 & 0.33 & 0.07 & 0.16 \\
$\mathrm{Al}_{2} \mathrm{O}_{3}$ & 15.8 & 16.6 & 16.5 & 15.5 & 14.0 & 14.9 \\
$\mathrm{Fe}_{2} \mathrm{O}_{3}$ & 1.23 & 1.21 & 1.22 & 0.75 & 0.88 & 0.49 \\
$\mathrm{FeO}$ & 2.29 & 2.56 & 2.36 & 1.41 & 1.30 & 0.81 \\
$\mathrm{MnO}$ & 0.06 & 0.06 & 0.05 & 0.03 & 0.01 & 0.03 \\
$\mathrm{CaO}$ & 3.17 & 3.00 & 3.17 & 1.39 & 0.02 & 0.50 \\
$\mathrm{MgO}$ & 1.47 & 1.76 & 1.74 & 0.84 & 0.29 & 0.25 \\
$\mathrm{~K}_{2} \mathrm{O}$ & 2.21 & 3.14 & 2.73 & 3.55 & 4.63 & 4.34 \\
$\mathrm{Na}$ & 4.40 & 3.76 & 4.29 & 3.67 & 0.37 & 3.57 \\
$\mathrm{P}_{2} \mathrm{O}$ & 0.21 & 0.27 & 0.25 & 0.22 & 0.11 & 0.40 \\
LOI & 1.40 & 1.41 & 1.55 & 1.84 & 2.01 & 1.26 \\
$\quad \mathrm{Total}$ & 99.8 & 99.6 & 99.5 & 99.9 & 99.6 & 99.7 \\
$n$ & 12 & 20 & 19 & 9 & 3 & 11 \\
\hline
\end{tabular}

Values given in percent; $n$, number of samples. positions of the distinct petrographical units (Figure 2a) are depicted in Table 1. The basic dikes are amphibolites, metadiabases, and diabases.

\section{Mineralogy}

The mineralogical compositions of the granitoid units are given in Tables 2 and 3 . For each mineral the right-hand values were determined by mean modal analyses [Portugal Ferreira et

Table 2. Average Mineralogical Compositions of the Grantoid Units in the Fundão Area

\begin{tabular}{llclcc}
\hline Lithotype & Quartz & Plagioclase & K-spar & Biotite & Muscovite \\
\hline$\Delta_{0}$ & 23,30 & 52,50 & 14,3 & 11,16 & $\ldots$ \\
$\Delta_{1}$ & 21,30 & 49,41 & 18,12 & 12,16 & $\ldots$ \\
$\Delta_{2}$ & 23,31 & 48,45 & 16,7 & 13,17 & $\ldots$ \\
$\gamma \Delta_{3}$ & 31,36 & 36,29 & 21,25 & 12,10 & $\ldots$ \\
$\gamma_{5}$ & 50,33 & 13,36 & 26,18 & 2,2 & 9,11 \\
$\gamma_{8}$ & $35, \mathrm{NG}$ & $30, \mathrm{NG}$ & $26, \mathrm{NG}$ & $2, \mathrm{NG}$ & $8, \mathrm{NG}$ \\
\hline
\end{tabular}

Values in weight percent. Cf. Figure 2a. The right-hand values under each mineral name was calculated by Portugal Ferreira et al. [1985] using mean modal analysis; the left-hand values in each column were obtained from normative calculations (CIPW norm) using the chemical compositions given in Table 1. NG, not given by Portugal Ferreira et al. [1985]. 
Table 3. Anorthite Content of the Plagioclases in the Various Grantoid Units

\begin{tabular}{cc}
\hline Lithotype & An, \% \\
\hline$\Delta_{0}$ & $25-30,20-33$ \\
$\Delta_{1}$ & $8-32,20-33$ \\
$\Delta_{2}$ & $11-45,24-30$ \\
$\gamma_{3}$ & $6-20,22-44$ \\
$\gamma_{5}$ & $0,20-45$ \\
$\gamma_{8}$ & $0-17, \mathrm{NG}$ \\
\hline
\end{tabular}

Cf. Figure 2a. See Table 2 for additional information.

al., 1985], whereas the left-hand values were calculated by a CIPW norm using the chemical compositions of the 74 rock samples collected in the Fundão area. The average anorthite (An) contents of the plagioclases are plotted, and some An isolines are drawn (Figure 2b). CIPW normative calculations give average compositions and do not reveal changes in composition related to zonation of plagioclases. Costa [1971] mentions that in the $\gamma_{5}$ and $\gamma \Delta_{3}$ granitoids plagioclase has a homogeneous composition (An 10 and An 20, respectively), whereas in the central plutonite $\left(\Delta_{0-2}\right)$ the plagioclases are strongly zonated (the composition of single minerals may vary in composition from An 18 to An 37). The composition of the biotites is shown in Table 4. The basic dikes are characterized by the major minerals [Portugal Ferreira, 1982]: amphibolites: hornblende, andesine (An 40-50); metadiabases: hornblende, andesine (An 40-50); and diabases: augite, labradorite (An $50-70)$. The composition of aplitic dikes in the area was determined by Costa et al. [1971]. In addition to the more weathering-resistant minerals quartz, potassium feldspar, and muscovite, these aplites contain albite or sodic oligoclase and biotite.

\section{Soils}

The soils in the Fundão area have a homogeneous mineralogical composition, defined by the association quartz + feldspar + biotite + halloysite, with small amounts of smectite,
Table 4. Chemical Compositions of Three Representative Biotites in the Fundão Area

\begin{tabular}{lrrr}
\hline & \multicolumn{3}{c}{ Color } \\
\cline { 2 - 4 } & Brown & Green to Brown & Green \\
\hline $\mathrm{SiO}_{2}$ & 36.78 & 27.39 & 37.96 \\
$\mathrm{TiO}_{2}$ & 2.68 & 2.66 & 2.98 \\
$\mathrm{Al}_{2} \mathrm{O}_{3}$ & 15.75 & 16.19 & 15.01 \\
$\mathrm{Fe}_{2} \mathrm{O}_{3}$ & 3.90 & 3.15 & 4.58 \\
$\mathrm{FeO}$ & 16.77 & 16.86 & 14.91 \\
$\mathrm{MnO}$ & 0.26 & 0.27 & 0.28 \\
$\mathrm{CaO}$ & 0.11 & 0.14 & 0.05 \\
$\mathrm{MgO}$ & 8.34 & 8.76 & 8.96 \\
$\mathrm{~K}_{2} \mathrm{O}$ & 9.93 & 9.04 & 9.67 \\
$\mathrm{Na}_{2} \mathrm{O}$ & 0.69 & 0.84 & 0.75 \\
$\mathrm{P}_{2} \mathrm{O}_{5}$ & 0.29 & 0.30 & 0.26 \\
$\mathrm{H}_{2} \mathrm{O}^{+}$ & 3.60 & 3.12 & 3.16 \\
\hline
\end{tabular}

Portugal Ferreira et al. [1985]. Values given in percent.

vermiculite, chlorite, and muscovite [Costa et al., 1971]. During the weathering of the rocks, biotite may have been altered to vermiculite, smectite, or even halloysite, and plagioclase to halloysite. The southeastern part of the plutonite is more deeply weathered than the northwestern part, probably because the southeastern part of the plutonite is covered by torrential deposits from the Serra da Gardunha. Furthermore, the $\gamma \Delta_{3}$ granite has been very intensively weathered, because this unit is clenched between the more consistent schist rings that have often been metamorphozed to hornfelses [Van der Weijden et al., 1983].

\section{Water-Rock Interactions}

Not all the minerals present in the various rocks of the plutonite are important as weathering reactants. The weathering products are mainly derived from plagioclase and biotite. Different degrees of weathering are found in different parts of the Fundão area: the SE part is more deeply affected than the

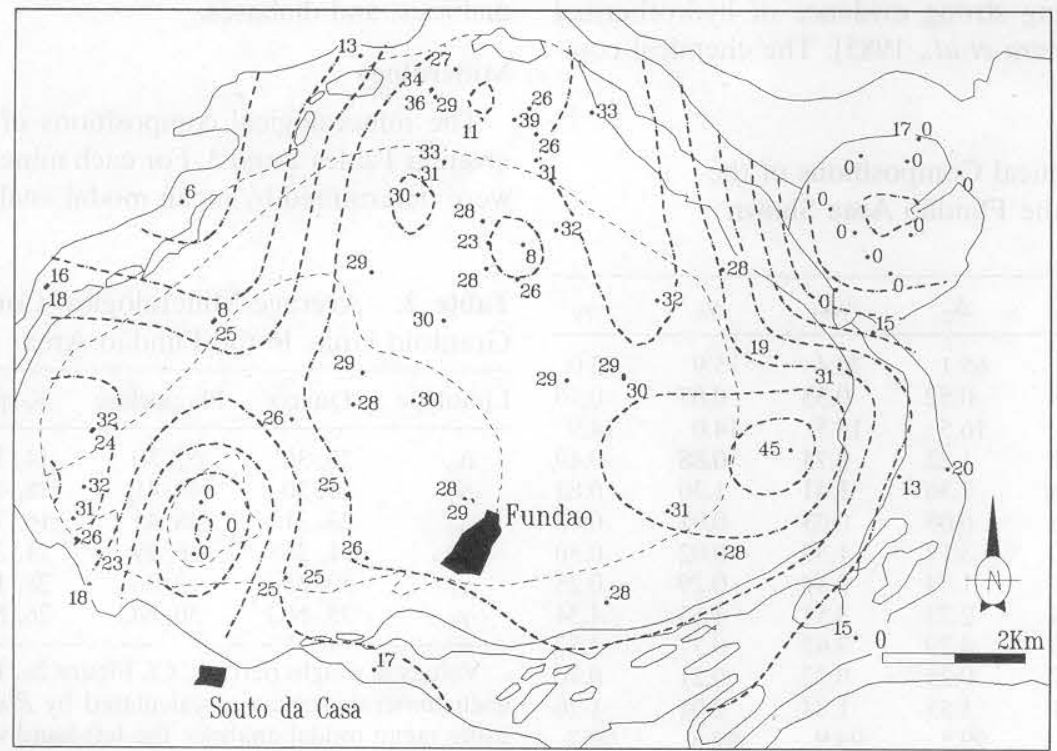

Figure $\mathbf{2 b}$. Contours of iso-anorthite contents (5\% increments) of plagioclases, calculated on the basis of analyses of 74 rock samples collected in the Fundão area. 
Table 5a. Assumed Weathering Model for the Plutonite

\begin{tabular}{|c|c|c|c|}
\hline \multirow{2}{*}{$\begin{array}{c}\text { Major } \\
\text { Primary } \\
\text { Minerals }\end{array}$} & \multicolumn{3}{|c|}{ Weathering Products/Processes } \\
\hline & Light & Moderate & Intensive \\
\hline \multicolumn{4}{|l|}{ Plagioclase } \\
\hline Plutonite* & a & a & a \\
\hline Faults† & b & b & b \\
\hline \multicolumn{4}{|l|}{ Biotite } \\
\hline Plutonite* & $\mathrm{c}$ & d & d \\
\hline Faultst & $\mathrm{e}$ & $\mathrm{e}$ & $\mathrm{e}$ \\
\hline
\end{tabular}

Plagioclase: An 7 for $\gamma_{5}$ and $\gamma_{8}$; An 20 for $\gamma \Delta_{3}$; An 20-40 for $\Delta_{0-2}$. Here a, halloysite; $\mathrm{b},\left(c_{1}\right)$ Ca-montmorillonite $+\left(1-c_{1}\right)$ halloysite; c, unweathered; d, $\left(c_{1}\right)$ vermiculite $+\left(1-c_{1}\right)$ halloysite; e, $\left(c_{1}\right)$ vermiculite $+\left(1-c_{1}\right)$ halloysite; $0 \leq c_{1} \leq 1$.

"Relatively good drainage conditions.

$\doteqdot$ More stagnant conditions.

$\mathrm{NW}$, and the $\gamma \Delta_{3}$ granite has been intensively weathered. The $\mathrm{N} 35 \mathrm{E}$ fault system may also control the water chemistry by creating more stagnant conditions of flow. These aspects are considered in Table 5a. A similar dominance of reactions was taken into account by Tardy et al. [1973] for the weathering of granites in temperate climates. Where dikes cross the plutonite they may also control the water chemistry. The most probable alteration processes that occur in the aplitic and basic dikes are represented in Table $5 b$.

\section{Sampling and Analysis}

Samples from springs and wells in the Fundão area were collected for several years in succession. The locations of 160 sampling sites are shown in Figure 3. The analytical methods that were used have been described by Van der Weijden et al. [1983]. These methods will be briefly summarized here. Conductance (Ec) and $p \mathrm{H}$ were measured immediately at the sampling site. In a field laboratory alkalinity was determined, using the Gran plot method, within 24 hours after collecting the samples.

In the home laboratory sodium, potassium, magnesium, and
Table 5b. Assumed Weathering Model for the Dikes

\begin{tabular}{|c|c|}
\hline Rock Type & Weathering Reactions of the Major Minerals \\
\hline $\mathrm{pl}$ & albi \\
\hline $\begin{array}{l}\text { Amphibolites and } \\
\text { metadiabases }\end{array}$ & $\begin{array}{l}\text { andesine } \rightarrow\left(c_{1}\right) \text { MgCa-montmorillonite }+ \\
\quad\left(1-c_{1}\right) \text { halloysite } \\
\text { hornblende } \rightarrow\left(c_{1}\right) \mathrm{MgCa} \text {-montmorillonite }+ \\
\quad\left(1-c_{1}\right) \text { chlorite }\end{array}$ \\
\hline Diabas & $\begin{array}{l}\text { labradorite } \rightarrow\left(c_{1}\right) \mathrm{MgCa} \text {-montmorillonite }+ \\
\quad\left(1-c_{1}\right) \text { halloysite } \\
\text { augite } \rightarrow\left(c_{1}\right) \text { MgCa-montmorillonite }+ \\
\quad\left(1-c_{1}\right) \text { chlorite }\end{array}$ \\
\hline
\end{tabular}

Plagioclase: An 7 for the aplites, An 40 for the amphibolites and metadiabases, and An 60 for the diabases; $0 \leq c_{1} \leq 1$.

calcium were determined by routine atomic absorption (AAS) or inductively coupled plasma spectrometry (ICP-AES). The sulphate concentration was determined by turbidimetry or by ICP-AES. The phosphate, silica, and nitrate concentrations were determined by colorimetry. House standards were used for calibration. The relative standard deviations for the individual concentrations were in most cases less than $5 \%$. The deviation of the charge balance was less than $10 \%$ of the total ionic charge. As one might expect, the higher relative deviations within this range were usually found for samples with low concentrations of dissolved components.

\section{Grouping Water Samples With Similar Chemistries: The RST Algorithm}

\section{Partitioning Methods}

Conventional partitioning methods [cf. Hartigan, 1975; Everitt, 1977] construct clusters from a data set. The number of clusters, $k$, is given by the user, and each object must belong to one group only. In order to obtain the $k$ clusters, some methods select $k$ representative objects in the data set, and the corresponding clusters are then found by assigning each remaining object to the nearest representative object. Fuzzy methods also construct $k$ clusters, but they avoid hard deci-

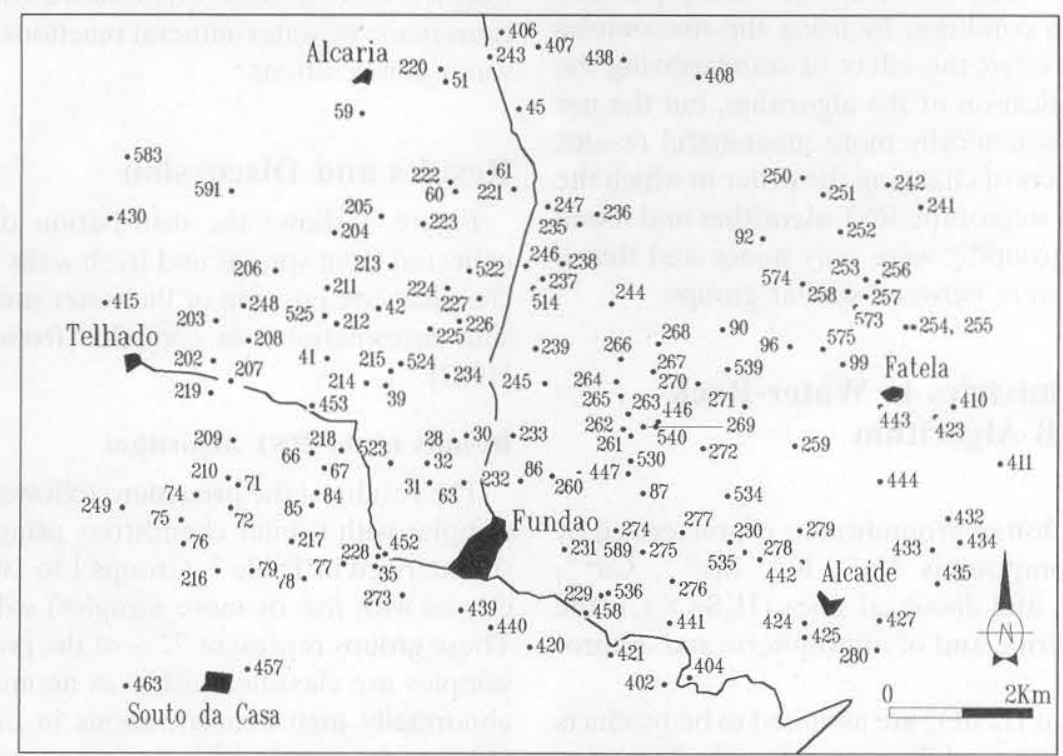

Figure 3. Distribution of the 160 spring and well water samples collected in the Fundão area. 
sions by using the fuzziness principle. Instead of deciding that an object belongs to cluster 1 , fuzzy methods can, for example, decide that $70 \%$ of an object belongs to cluster $1,20 \%$ to cluster 2 , and $10 \%$ to cluster 3 . This means that the object should probably be assigned to cluster 1 but that there is still doubt about whether it should be assigned to cluster 2 or 3 [Kaufman and Rousseeuw, 1990].

Conventional and fuzzy methods need a priori good estimates of the number of groups present in the data set. This is often impossible when one is dealing with groundwater data sets because the number of groups that are present will depend on (1) the number of rock types in the area, (2) the degree of chemical weathering of various rock types, and (3) inputs from sources other than water-rock interactions. All these factors affect the water composition and in combination may generate a high number of water groups. These clustering methods also assume that the variables measured on each object (water sample) belong to normal or lognormal populations, which in many cases might be a hard assumption.

\section{Partitioning Using the Concept of Equivalent Relations}

In order to avoid the drawbacks of the conventional clustering methods, we were in need of a more powerful method to identify water samples with similar chemistries. In mathematical terminology water samples within these groups will have equivalent relations, meaning that they are in the same equivalence class of "sameness" by their chemistries. The reflexive, symmetric, and transitive (RST) algorithm has been developed for finding groups of water samples with similar chemistries in a data set. A full description of the algorithm is given in Appendix 1.

\section{Grouping the Water Samples}

\section{From the Fundão Data Set}

As mentioned in Appendix 1, the results obtained with the RST algorithm depend on the scale in which the data are expressed. We applied the algorithm to the data set in the micromoles per liter and microequivalents per liter scales, but we obtained the most meaningful results using the micrograms per liter scale. The better performance of the latter scale might be due to avoidance of a closed-sum effect by introducing the charge balance condition using the microequivalents per liter scale or approaching this condition by using the micromoles per liter scale. We also tested the effect of standardizing the data set prior to the application of the algorithm, but the use of the raw data gave geochemically more meaningful results. Finally, we tested the effects of changing the order in which the data are used in the third step of the RST algorithm and found that the changes in the grouping were only minor and that if changes occurred, these were between similar groups.

\section{Relating Water Chemistries to Water-Rock Interactions: The SiB Algorithm \\ Water-Rock Interactions}

The chemical composition of groundwater, characterized by the major inorganic compounds $\mathrm{Na}^{+}, \mathrm{K}^{+}, \mathrm{Mg}^{2+}, \mathrm{Ca}^{2+}$, $\mathrm{HCO}_{3}^{-}, \mathrm{Cl}^{-}, \mathrm{SO}_{4}^{2-}, \mathrm{NO}_{3}^{-}$and dissolved silica $\left(\mathrm{H}_{2} \mathrm{SiO}_{3}^{\circ}\right)$, is the result of chemical weathering and of atmospheric and anthropogenic inputs.

All dissolved $\mathrm{HCO}_{3}^{-}$and $\mathrm{H}_{2} \mathrm{SiO}_{3}^{\circ}$ are assumed to be products of chemical weathering of autochthonous minerals. This condition is not met in areas with sizable input of limestone dust or application of calcium carbonate on agricultural land, which, as mentioned already, can be neglected in this area. We also have no indications for secondary precipitation of carbonate or silica. Alkalinity of groundwater may change, either by selective uptake of nitrate in exchange with bicarbonate or by harvesting of crops which have taken up cations in excess over anions from soil water in exchange with protons. For a region with a mixture of agriculture, viniculture, fruit culture, forestry, and uncultivated areas with grasses and scrubs, it is impossible to quantify the net effect of such changes in alkalinity. We assume that in the Fundão region these processes have relatively little effect on the general level of alkalinity acquired by water-rock interactions under soil $P_{\mathrm{CO}_{2}}$. We also assume that loss of dissolved silica by uptake in harvested crops is negligible. Garrels [1967] showed that dissolved $\mathrm{HCO}_{3}^{-}$and $\mathrm{H}_{2} \mathrm{SiO}_{3}^{\circ}$ and their ratios are good diagnostic parameters for particular water-mineral interactions. As a working hypothesis, dissolved $\mathrm{Cl}^{-}, \mathrm{SO}_{4}^{2-}$ and $\mathrm{NO}_{3}^{-}$are considered to come from atmospheric and pollution sources. The presence of pyrite as a potential source of sulphate can be neglected in the area. The concentration of each cation is separated in two partial contributions, one related to the weathering reactions, and the other related to pollution. In order to quantify these partial contributions we developed a weathering algorithm, which we called the SiB (silica-bicarbonate) algorithm. This algorithm is described in detail in Appendix 2.

\section{Relating Water Compositions to Chemical Weathering of Rock-Forming Minerals}

We used the $\mathrm{SiB}$ algorithm to relate water compositions to weathering reactions. In brief, the assumption made in this algorithm is that dissolved silica and bicarbonate are exclusively produced by chemical weathering of the dominant primary minerals into secondary (clays) minerals. The other major anions are considered to have come from atmospheric and anthropogenic sources. Knowing the principal primary rockforming minerals in the area and their most likely weathering products, the $\mathrm{SiB}$ algorithm uses stoichiometries of the weathering reactions to relate the chemistries of groups of water, as identified using the RST algorithm, to the contributions of water-rock interactions as well as of other sources. In this manner we can make quantitative estimates of the contributions made by water-mineral reactions and other sources to the water compositions.

\section{Results and Discussion}

Figure 3 shows the distribution of a set of 160 samples collected from springs and fresh wells in the Fundão area. The chemical composition of the water samples is given in Table 6. This information was compiled from Van der Weijden et al. [1983].

\section{Results of the RST Algorithm}

The results of the procedure followed to find groups of water samples with similar chemistries using the RST algorithm are summarized in Table 7. Groups 1 to 10 of Table 7 (equivalence classes with five or more samples) will be considered further. These groups represent $72 \%$ of the population. The remaining samples are classified either as anomalies, because they have abnormally high concentrations in one or more of the ions ( $12 \%$ of the population), or as scattered samples, because they do not show any remarkable characteristic $(16 \%)$. The anom- 
Table 6. Data Set

\begin{tabular}{|c|c|c|c|c|c|c|c|c|c|c|}
\hline $\mathrm{Nr}$ & $\mathrm{T}$ & $\mathrm{Na}^{+}$ & $\mathrm{K}^{+}$ & $\mathrm{Mg}^{2+}$ & $\mathrm{Ca}^{2+}$ & $\mathrm{Cl}^{-}$ & $\mathrm{SO}_{4}^{2-}$ & $\mathrm{NO}_{3}^{-}$ & $\mathrm{HCO}_{3}^{-}$ & $\mathrm{H}_{2} \mathrm{SiO}_{3}^{\circ}$ \\
\hline 28 & 3 & 613 & 39 & 245 & 433 & 447 & 178 & 371 & 780 & 656 \\
\hline 30 & 3 & 691 & 38 & 242 & 468 & 493 & 229 & 460 & 844 & 639 \\
\hline 31 & 2 & 613 & 15 & 129 & 315 & 430 & 93 & 387 & 490 & 506 \\
\hline 32 & 3 & 491 & 31 & 100 & 260 & 287 & 65 & 371 & 390 & 558 \\
\hline 35 & 3 & 639 & 25 & 183 & 320 & 353 & 171 & 221 & 729 & 614 \\
\hline 39 & 2 & 406 & 17 & 121 & 128 & 235 & 65 & 216 & 620 & 260 \\
\hline 41 & 3 & 332 & 19 & 74 & 180 & 192 & 99 & 55 & 261 & 463 \\
\hline 42 & 3 & 396 & 8 & 58 & 8 & 132 & 63 & 139 & 370 & 421 \\
\hline 45 & 2 & 1070 & 55 & 387 & 488 & 680 & 232 & 121 & 1280 & 571 \\
\hline 51 & 2 & 817 & 36 & 275 & 650 & 508 & 229 & 189 & 780 & 100 \\
\hline 59 & 2 & 1683 & 52 & 683 & 1142 & 2152 & 318 & 150 & 2260 & 674 \\
\hline 60 & 3 & 433 & 13 & 126 & 217 & 252 & 79 & 63 & 561 & 524 \\
\hline 61 & 3 & 439 & 11 & 93 & 158 & 235 & 42 & 18 & 580 & 560 \\
\hline 63 & 2 & 704 & 76 & 300 & 622 & 803 & 367 & 998 & 229 & 399 \\
\hline 66 & 3 & 530 & 7 & 192 & 325 & 301 & 162 & 366 & 480 & 474 \\
\hline 67 & 3 & 591 & 9 & 129 & 236 & 247 & 2 & $\gg 0$ & 1052 & 684 \\
\hline 71 & 3 & 470 & 16 & 192 & 199 & 186 & 217 & 5 & 639 & 626 \\
\hline 72 & 3 & 330 & 6 & 19 & 13 & 166 & 28 & 1 & 239 & 478 \\
\hline 74 & 3 & 424 & 14 & 80 & 146 & 152 & 22 & 32 & 661 & 609 \\
\hline 75 & 2 & 313 & 7 & 105 & 88 & 141 & 31 & 1 & 480 & 399 \\
\hline 76 & 2 & 374 & 11 & 150 & 200 & 158 & 46 & 5 & 810 & 503 \\
\hline 77 & 3 & 792 & 20 & 204 & 405 & 560 & 119 & 258 & 851 & 499 \\
\hline 78 & 2 & 1796 & 197 & 400 & 630 & 1693 & 236 & 875 & 918 & 438 \\
\hline 79 & 3 & 407 & 11 & 113 & 136 & 184 & 63 & 121 & 410 & 634 \\
\hline 84 & 3 & 509 & 7 & 171 & 221 & 313 & 161 & 211 & 451 & 426 \\
\hline 85 & 3 & 425 & 9 & 88 & 221 & 172 & 47 & 82 & 590 & 606 \\
\hline 86 & 3 & 570 & 25 & 183 & 200 & 284 & 18 & 60 & 870 & 663 \\
\hline 87 & 3 & 470 & 2 & 92 & 123 & 247 & 89 & 1 & 451 & 613 \\
\hline 90 & 3 & 535 & 11 & 150 & 181 & 252 & 63 & 47 & 761 & 506 \\
\hline 92 & 2 & 452 & 14 & 92 & 145 & 189 & 58 & $\gg 0$ & 580 & 552 \\
\hline 96 & 2 & 591 & 11 & 75 & 73 & 341 & 29 & 32 & 480 & 652 \\
\hline 99 & 2 & 752 & 21 & 171 & 248 & 577 & 183 & 37 & 600 & 353 \\
\hline 202 & 2 & 856 & 43 & 419 & 708 & 1320 & 654 & 840 & 139 & 573 \\
\hline 203 & 2 & 677 & 25 & 196 & 272 & 379 & 209 & 185 & 610 & 440 \\
\hline 204 & 2 & 527 & 11 & 114 & 126 & 258 & 865 & 158 & 352 & 657 \\
\hline 205 & 2 & 748 & 23 & 296 & 375 & 545 & 202 & 380 & 716 & 485 \\
\hline 206 & 2 & 731 & 21 & 156 & 207 & 689 & 145 & 37 & 472 & 441 \\
\hline 207 & 2 & 708 & 13 & 236 & 422 & 631 & 238 & 500 & 244 & 489 \\
\hline 208 & 3 & 433 & 11 & 75 & 88 & 184 & 86 & 92 & 328 & 474 \\
\hline 209 & 2 & 567 & 21 & 107 & 213 & 235 & 161 & 240 & 367 & 532 \\
\hline 210 & 3 & 362 & 11 & 45 & 75 & 186 & 38 & 82 & 389 & 626 \\
\hline 211 & 2 & 716 & 69 & 232 & 381 & 402 & 192 & 71 & 1080 & 587 \\
\hline 212 & 3 & 397 & 27 & 70 & 130 & 86 & 86 & 143 & 357 & 603 \\
\hline 213 & 2 & 830 & 32 & 337 & 556 & 703 & 216 & 855 & 429 & 405 \\
\hline 214 & 3 & 528 & 11 & 112 & 229 & 224 & 219 & 203 & 215 & 437 \\
\hline 215 & 3 & 457 & 345 & 125 & 170 & 123 & 87 & 18 & 690 & 564 \\
\hline 216 & 3 & 518 & 14 & 213 & 356 & 192 & 113 & 53 & 1113 & 660 \\
\hline 217 & 3 & 541 & 11 & 90 & 225 & 247 & 45 & 3 & 787 & 654 \\
\hline 218 & 2 & 604 & 88 & 302 & 1306 & 493 & 114 & 181 & 2995 & 635 \\
\hline 219 & 3 & 710 & 53 & 238 & 457 & 775 & 69 & 877 & 167 & 465 \\
\hline 220 & 2 & 1968 & 155 & 2163 & 1133 & 2524 & 524 & 1081 & 3656 & 264 \\
\hline 221 & 2 & 495 & 11 & 94 & 139 & 212 & 68 & 3 & 477 & 522 \\
\hline 222 & 3 & 538 & 23 & 172 & 285 & 264 & 97 & 216 & 642 & 634 \\
\hline 223 & 3 & 530 & 11 & 218 & 308 & 258 & 185 & 435 & 326 & 485 \\
\hline 224 & 3 & 359 & 57 & 162 & 386 & 132 & 69 & 77 & 1156 & 411 \\
\hline 225 & 3 & 393 & 15 & 71 & 155 & 135 & 113 & 58 & 372 & 472 \\
\hline 226 & 2 & 387 & 16 & 132 & 66 & 114 & 79 & 85 & 436 & 545 \\
\hline 227 & 3 & 409 & 27 & 80 & 186 & 126 & 77 & 226 & 367 & 581 \\
\hline 228 & 3 & 667 & 41 & 201 & 328 & 272 & 171 & 177 & 836 & 750 \\
\hline 229 & 3 & 880 & 40 & 140 & 230 & 545 & 81 & 205 & 557 & 666 \\
\hline 230 & 3 & 666 & 11 & 136 & 210 & 206 & 159 & 21 & 664 & 546 \\
\hline 231 & 3 & 592 & 15 & 127 & 330 & 181 & 224 & 124 & 626 & 508 \\
\hline 232 & 2 & 565 & 33 & 75 & 213 & 178 & 40 & 435 & 334 & 745 \\
\hline 233 & 2 & 1227 & 82 & 603 & 1165 & 803 & 257 & 2903 & 690 & 687 \\
\hline 234 & 3 & 443 & 11 & 89 & 215 & 161 & 139 & 132 & 433 & 670 \\
\hline 235 & 3 & 473 & 25 & 43 & 147 & 158 & 35 & 65 & 523 & 668 \\
\hline 236 & 2 & 1265 & 74 & 503 & 1192 & 1377 & 572 & 1387 & 602 & 586 \\
\hline 237 & 3 & 427 & 12 & 74 & 154 & 120 & 48 & 248 & 400 & 207 \\
\hline 238 & 3 & 403 & 11 & 68 & 109 & 143 & 68 & 68 & 438 & 535 \\
\hline 239 & 3 & 633 & 62 & 219 & 392 & 330 & 137 & 500 & 600 & 558 \\
\hline 241 & 3 & 256 & 12 & 33 & 41 & 80 & 12 & 61 & 231 & 514 \\
\hline 242 & 3 & 215 & 11 & 9 & 22 & 66 & 5 & 71 & 136 & 445 \\
\hline
\end{tabular}


Table 6. (continued)

\begin{tabular}{|c|c|c|c|c|c|c|c|c|c|c|}
\hline $\mathrm{Nr}$ & $\mathrm{T}$ & $\mathrm{Na}^{+}$ & $\mathrm{K}^{+}$ & $\mathrm{Mg}^{2+}$ & $\mathrm{Ca}^{2+}$ & $\mathrm{Cl}^{-}$ & $\mathrm{SO}_{4}^{2-}$ & $\mathrm{NO}_{3}^{-}$ & $\mathrm{HCO}_{3}^{-}$ & $\mathrm{H}_{2} \mathrm{SiO}_{3}^{\circ}$ \\
\hline 243 & 2 & 1097 & 109 & 486 & 763 & 890 & 258 & 435 & 1529 & 776 \\
\hline 244 & 3 & 656 & 18 & 105 & 254 & 270 & 168 & 250 & 323 & 476 \\
\hline 245 & 2 & 536 & 29 & 153 & 265 & 316 & 87 & 131 & 692 & 608 \\
\hline 246 & 3 & 493 & 11 & 99 & 170 & 129 & 76 & 131 & 564 & 519 \\
\hline 247 & 3 & 593 & 13 & 125 & 269 & 287 & 186 & 167 & 454 & 532 \\
\hline 248 & 2 & 656 & 24 & 196 & 347 & 198 & 192 & 500 & 526 & 415 \\
\hline 249 & 3 & 418 & 12 & 83 & 83 & 109 & 85 & 52 & 408 & 560 \\
\hline 250 & 3 & 711 & 31 & 163 & 124 & 273 & 139 & 324 & 187 & 579 \\
\hline 251 & 3 & 316 & 16 & 15 & 24 & 95 & 8 & 35 & 203 & 467 \\
\hline 252 & 3 & 283 & 11 & 12 & 23 & 106 & 3 & 66 & 128 & 414 \\
\hline 253 & 2 & 356 & 11 & 24 & 31 & 92 & 33 & 61 & 249 & 619 \\
\hline 254 & 3 & 345 & 16 & 69 & 45 & 118 & 37 & 29 & 296 & 600 \\
\hline 255 & 3 & 383 & 11 & 66 & 47 & 126 & 36 & 66 & 293 & 672 \\
\hline 256 & 3 & 385 & 11 & 38 & 32 & 132 & 38 & 35 & 236 & 520 \\
\hline 257 & 3 & 474 & 11 & 72 & 60 & 146 & 50 & 140 & 243 & 613 \\
\hline 258 & 3 & 184 & 11 & 12 & 14 & 98 & 5 & 66 & 59 & 237 \\
\hline 259 & 3 & 635 & 29 & 210 & 234 & 267 & 87 & 190 & 723 & 740 \\
\hline 260 & 3 & 481 & 12 & 102 & 140 & 143 & 31 & 43 & 648 & 760 \\
\hline 261 & 2 & 1177 & 93 & 296 & 517 & 947 & 183 & 452 & 675 & 620 \\
\hline 262 & 2 & 2312 & 113 & 700 & 1254 & 3385 & 375 & 1516 & 1048 & 617 \\
\hline 263 & 2 & 1846 & 93 & 1051 & 1827 & 3213 & 725 & 1241 & 1724 & 740 \\
\hline 264 & 3 & 549 & 16 & 114 & 252 & 338 & 102 & 250 & 451 & 550 \\
\hline 265 & 3 & 407 & 11 & 59 & 90 & 155 & 22 & 9 & 567 & 697 \\
\hline 266 & 2 & 1123 & 36 & 586 & 1018 & 1320 & 892 & 532 & 1278 & 486 \\
\hline 267 & 2 & 938 & 46 & 294 & 78 & 574 & 56 & 182 & 1278 & 739 \\
\hline 268 & 2 & 740 & 27 & 231 & 377 & 537 & 220 & 282 & 526 & 581 \\
\hline 269 & 2 & 3889 & 193 & 663 & 1794 & 6886 & 559 & 1048 & 877 & 567 \\
\hline 270 & 2 & 1016 & 55 & 799 & 855 & 1348 & 338 & 726 & 1169 & 452 \\
\hline 271 & 3 & 481 & 18 & 72 & 856 & 218 & 25 & 139 & 449 & 842 \\
\hline 272 & 3 & 365 & 26 & 85 & 126 & 264 & 6 & 187 & 367 & 573 \\
\hline 273 & 3 & 359 & 19 & 65 & 144 & 166 & 12 & 4 & 554 & 723 \\
\hline 274 & 3 & 492 & 11 & 108 & 105 & 310 & 52 & 150 & 470 & 530 \\
\hline 275 & 3 & 417 & 27 & 89 & 107 & 287 & 13 & 105 & 516 & 662 \\
\hline 276 & 3 & 547 & 15 & 135 & 223 & 488 & 35 & 176 & 531 & 615 \\
\hline 277 & 3 & 447 & 49 & 143 & 191 & 367 & 59 & 113 & 606 & 736 \\
\hline 278 & 3 & 359 & 11 & 54 & 75 & 207 & 18 & 113 & 375 & 760 \\
\hline 279 & 3 & 690 & 22 & 158 & 212 & 602 & 67 & 118 & 688 & 692 \\
\hline 280 & 3 & 271 & 43 & 43 & 90 & 155 & 11 & 13 & 434 & 583 \\
\hline 402 & 3 & 165 & 24 & 25 & 34 & 116 & 7 & 22 & 150 & 211 \\
\hline 404 & 3 & 266 & 24 & 43 & 105 & 192 & 10 & 32 & 308 & 399 \\
\hline 406 & 3 & 987 & 33 & 127 & 195 & 634 & 75 & 60 & 853 & 692 \\
\hline 407 & 2 & 1152 & 67 & 446 & 676 & 757 & 200 & 106 & 2081 & 757 \\
\hline 408 & 3 & 430 & 34 & 181 & 76 & 273 & 70 & 112 & 551 & 711 \\
\hline 410 & 3 & 290 & 27 & 78 & 47 & 109 & 12 & 74 & 272 & 530 \\
\hline 411 & 2 & 177 & 48 & 122 & 75 & 202 & 46 & 30 & 214 & 209 \\
\hline 415 & 3 & 465 & 6 & 115 & 42 & 248 & 17 & 8 & 470 & 612 \\
\hline 420 & 3 & 313 & 15 & 53 & 108 & 213 & 23 & 14 & 390 & 340 \\
\hline 421 & 3 & 317 & 31 & 70 & 97 & 192 & 22 & 23 & 353 & 339 \\
\hline 423 & 3 & 241 & 18 & 93 & 29 & 89 & 16 & 29 & 262 & 352 \\
\hline 424 & 3 & 468 & 26 & 78 & 119 & 236 & 39 & 81 & 365 & 445 \\
\hline 425 & 3 & 375 & 32 & 115 & 183 & 92 & 10 & 11 & 819 & 812 \\
\hline 427 & 3 & 354 & 38 & 61 & 101 & 165 & 5 & 30 & 433 & 534 \\
\hline 430 & 3 & 645 & 29 & 89 & 302 & 245 & 162 & 34 & 725 & 464 \\
\hline 432 & 3 & 368 & 39 & 43 & 57 & 164 & 9 & 25 & 338 & 689 \\
\hline 433 & 3 & 327 & 11 & 59 & 64 & 108 & 41 & 24 & 280 & 524 \\
\hline 434 & 3 & 239 & 31 & 48 & 52 & 80 & 8 & 13 & 292 & 524 \\
\hline 435 & 3 & 293 & 38 & 39 & 67 & 65 & 5 & 5 & 421 & 581 \\
\hline 438 & 2 & 454 & 47 & 68 & 57 & 155 & 30 & 30 & 430 & 487 \\
\hline 439 & 3 & 448 & 55 & 68 & 134 & 130 & 13 & $\gg 0$ & 714 & 709 \\
\hline 440 & 3 & 398 & 36 & 68 & 134 & 129 & 29 & 7 & 636 & 729 \\
\hline 441 & 3 & 472 & 47 & 129 & 237 & 172 & 33 & 8 & 957 & 875 \\
\hline 442 & 3 & 680 & 58 & 166 & 283 & 846 & 25 & 75 & 607 & 838 \\
\hline 443 & 3 & 475 & 45 & 156 & 147 & 384 & 33 & 33 & 549 & 569 \\
\hline 444 & 3 & 301 & 38 & 95 & 60 & 160 & 13 & 36 & 351 & 442 \\
\hline 446 & 3 & 488 & 34 & 102 & 171 & 260 & 14 & 33 & 651 & 887 \\
\hline 447 & 2 & 707 & 72 & 207 & 373 & 542 & 95 & 107 & 974 & 548 \\
\hline 452 & 3 & 669 & 50 & 198 & 332 & 344 & 176 & 105 & 838 & 774 \\
\hline 453 & 3 & 607 & 36 & 197 & 253 & 280 & 46 & 17 & 1124 & 752 \\
\hline 457 & 3 & 304 & 36 & 62 & 146 & 94 & 1 & 1 & 566 & 568 \\
\hline 458 & 3 & 330 & 35 & 66 & 148 & 196 & 9 & 22 & 526 & 670 \\
\hline 463 & 2 & 313 & 37 & 71 & 82 & 245 & 33 & 31 & 231 & 366 \\
\hline 514 & 2 & 371 & 31 & 96 & 188 & 164 & 66 & 27 & 558 & 497 \\
\hline 522 & 2 & 442 & 30 & 241 & 294 & 184 & 47 & 32 & 1150 & 600 \\
\hline
\end{tabular}


Table 6. (continued)

\begin{tabular}{rrrrrrrrrrr}
\hline $\mathrm{Nr}$ & $\mathrm{T}$ & $\mathrm{Na}^{+}$ & \multicolumn{1}{c}{$\mathrm{K}^{+}$} & $\mathrm{Mg}^{2+}$ & $\mathrm{Ca}^{2+}$ & $\mathrm{Cl}^{-}$ & $\mathrm{SO}_{4}^{2-}$ & $\mathrm{NO}_{3}^{-}$ & $\mathrm{HCO}_{3}^{-}$ & $\mathrm{H}_{2} \mathrm{SiO}_{3}^{\circ}$ \\
\hline 523 & 2 & 600 & 39 & 118 & 282 & 307 & 149 & 34 & 650 & 860 \\
524 & 2 & 576 & 63 & 145 & 293 & 252 & 114 & 21 & 919 & 679 \\
525 & 2 & 400 & 47 & 86 & 142 & 128 & 69 & 48 & 503 & 554 \\
530 & 2 & 669 & 37 & 168 & 316 & 462 & 178 & 62 & 643 & 742 \\
534 & 2 & 471 & 36 & 95 & 150 & 281 & 81 & 100 & 310 & 604 \\
535 & 2 & 548 & 113 & 245 & 404 & 737 & 143 & 105 & 625 & 568 \\
536 & 2 & 370 & 41 & 99 & 254 & 240 & 55 & 42 & 529 & 431 \\
539 & 2 & 566 & 51 & 100 & 289 & 697 & 113 & 150 & 600 & 375 \\
540 & 2 & 319 & 84 & 124 & 186 & 228 & 23 & 63 & 520 & 806 \\
573 & 2 & 177 & 35 & 28 & 29 & 199 & 10 & 19 & 96 & 280 \\
574 & 3 & 634 & 80 & 223 & 241 & 930 & 95 & 29 & 652 & 515 \\
575 & 2 & 596 & 81 & 223 & 224 & 433 & 130 & 30 & 876 & 514 \\
583 & 2 & 880 & 166 & 738 & 452 & 2390 & 134 & 284 & 305 & 415 \\
589 & 3 & 302 & 88 & 121 & 146 & 208 & 19 & 24 & 502 & 679 \\
591 & 2 & 450 & 134 & 183 & 285 & 419 & 209 & 20 & 572 & 228 \\
\hline
\end{tabular}

Chemical analyses (in $\mu \mathrm{M}$ ) of 160 water samples from the Fundão area. The sample numbers are given in the first column; their locations are shown in Figure 3. In the second column (T) the type of sampled water is given: 2 , fresh wells; 3 , springs.

alies were divided into two groups, one containing the anomalies in $\mathrm{HCO}_{3}^{-}$, and the other containing highly polluted samples (enriched in $\mathrm{SO}_{4}^{2-}$ and/or $\mathrm{Cl}^{-}$and/or $\mathrm{NO}_{3}^{-}$).

\section{Weathering Reactions Considered in the SiB Algorithm}

The SiB algorithm was applied to water groups 1 to 10 (Table 7). The weathering reactions used in the calculations were the ones from the weathering models already defined for the plutonite and for the dikes (Tables $5 \mathrm{a}$ and $5 \mathrm{~b}$ ). The assumed structural formulas of the primary minerals present in these rocks and of the secondary minerals formed upon chemical weathering are given in Table 8 . The extreme weathering reactions (the ones that form just one weathering product) for the plutonite and for the amphibolites are listed in Table 9. The results of the analysis of the water-rock interactions are presented in Table 10.

\section{Possible and Best-Fit Solutions of the SiB Algorithm}

No information is available about the relative abundances of the secondary minerals in the soils that have developed on the various rocks in the area. For this reason the $\mathrm{SiB}$ algorithm (Appendix 2) can generate only sets of possible solutions. We used information about the chemistry of the locally applied fertilizers to find a best-fit solution among the possible solutions. Chloride, sulphate, and nitrate are the major anionic constituents while calcium is a major cationic constituent of these fertilizers. As a best-fit solution among the possible solutions, we selected the one with the most significant Spearman rank-order correlation coefficient between the sum of these anions (in microequivalents per liter) and $\mathrm{Ca}$ (in microequivalents per liter). For the best-fit solution high correlation coefficients are also expected for $\mathrm{Mg}$ (fertilizers) and $\mathrm{Na}$ (mainly domestic effluents) because these cations are not taken up by plants as effectively as K.

\section{Results of the SiB Algorithm}

The best-fit weathering reactions, relating the water chemistries to the various rocks, are given in the third row of Table 10. For groups 6 and 10 these reactions are combinations of end-member reactions.

Figure 4 shows the correlation between the median concentrations of $\mathrm{Ca}^{2+}, \mathrm{Mg}^{2+}$, and $\mathrm{Na}^{+}$attributed to pollution (denoted by a "p" in Table 10, left-hand column) of groups 1 to 6 and 8 to 10 and the sum of the medium concentrations of $\mathrm{Cl}^{-}$, $\mathrm{SO}_{4}^{2-}$, and $\mathrm{NO}_{3}^{-}$. The corresponding Spearman coefficients are $0.90,0.95$, and 0.92 for probability levels of $99.991 \%, 99.999 \%$,

Table 7. Groups Obtained by the Equivalence-Classes Procedure

\begin{tabular}{|c|c|c|c|c|}
\hline Designation & Sample Numbers & $n$ & $\begin{array}{l}\% \\
\text { gr }\end{array}$ & $\begin{array}{c}\% \\
\text { cum }\end{array}$ \\
\hline 1 & $61,74,75,85,92,235,246,260,265,273,275,415,440,443,446,457,458,514,525,536,540,589$ & 22 & 14 & 14 \\
\hline 2 & $41,72,241,242,251,252,253,254,255,256,257,402,404,410,411,423,433,434,463,573$ & 20 & 13 & 27 \\
\hline 3 & $87,96,221,225,238,249,280,420,421,427,432,435,438,444$ & 14 & 9 & 36 \\
\hline 4 & $42,79,204,208,210,212,226,227,237,271,272,278,424,534$ & 14 & 9 & 45 \\
\hline 5 & $35,203,228,230,231,259,430,452,523,530$ & 10 & 6 & 51 \\
\hline 6 & $67,211,216,224,267,447,453,522$ & 8 & 5 & 56 \\
\hline 7 & $76,86,90,217,425,441,524,575$ & 8 & 5 & 61 \\
\hline 8 & $31,32,66,223,232,239,248$ & 7 & 4 & 65 \\
\hline 9 & $39,60,222,245,276,277,408$ & 7 & 4 & 69 \\
\hline 10 & $28,30,51,77,205$ & 5 & 3 & 72 \\
\hline Anomalies $\left(\mathrm{HCO}_{3}^{-}\right)$ & $45,59,218,220,243,407$ & 6 & 4 & 76 \\
\hline Anomalies (pollutants) & $63,78,202,213,219,233,236,262,263,266,269,270,583$ & 13 & 8 & 84 \\
\hline Scattered samples & $\begin{array}{l}71,84,99,206,207,209,214,215,229,234,244,247,250,258,261,264,268,274,279,406, \\
\quad 439,442,535,539,574,591\end{array}$ & 26 & 16 & 100 \\
\hline
\end{tabular}

Here $n$ is number of samples per group; \% gr, percentage of samples in each group relative to the total number of samples; $\%$ cum, cumulative percentage of the samples relative to the total number of samples in the given order of the groups. 
Table 8. Simplified Structural Compositions of the Primary Minerals Present in the Major Lithological Units and in Dikes

\begin{tabular}{|c|c|}
\hline Mineral & Chemical Formula* \\
\hline $\begin{array}{l}\text { Albite (An 7) } \\
\text { Oligoclase (An 20) } \\
\text { Oligoclase/andesine } \\
\quad \text { (An 30) }\end{array}$ & $\begin{array}{l}0.465 \mathrm{Na}_{2} \mathrm{O} \cdot 0.07 \mathrm{CaO} \cdot 0.535 \mathrm{Al}_{2} \mathrm{O}_{3} \cdot 2.93 \mathrm{SiO}_{2} \\
0.4 \mathrm{Na}_{2} \mathrm{O} \cdot 0.2 \mathrm{CaO} \cdot 0.6 \mathrm{Al}_{2} \mathrm{O}_{3} \cdot 2.8 \mathrm{SiO}_{2} \\
0.35 \mathrm{Na}_{2} \mathrm{O} \cdot 0.3 \mathrm{CaO} \cdot 0.65 \mathrm{Al}_{2} \mathrm{O}_{3} \cdot 2.7 \mathrm{SiO}_{2}\end{array}$ \\
\hline $\begin{array}{l}\text { Andesine (An 35) } \\
\text { Andesine (An 40) } \\
\text { Labradorite (An 60) }\end{array}$ & $\begin{array}{l}0.325 \mathrm{Na}_{2} \mathrm{O} \cdot 0.35 \mathrm{CaO} \cdot 0.675 \mathrm{Al}_{2} \mathrm{O}_{3} \cdot 2.65 \mathrm{SiO}_{2} \\
0.3 \mathrm{Na}_{2} \mathrm{O} \cdot 0.4 \mathrm{CaO} \cdot 0.7 \mathrm{Al}_{2} \mathrm{O}_{3} \cdot 2.6 \mathrm{SiO}_{2} \\
0.2 \mathrm{Na}_{2} \mathrm{O} \cdot 0.6 \mathrm{CaO} \cdot 0.8 \mathrm{Al}_{2} \mathrm{O}_{3} \cdot 2.4 \mathrm{SiO}_{2}\end{array}$ \\
\hline $\begin{array}{l}\text { Biotite } \\
\text { Hornblende } \\
\text { Augite }\end{array}$ & $\begin{array}{l}0.1 \mathrm{Na}_{2} \mathrm{O} \cdot 0.9 \mathrm{~K}_{2} \mathrm{O} \cdot 2 \mathrm{MgO} \cdot 2.1 \mathrm{FeO} \cdot 0.2 \mathrm{Fe}_{2} \mathrm{O}_{3} \cdot 0.3 \mathrm{TiO}_{2} \cdot 1.5 \\
\mathrm{Al}_{2} \mathrm{O}_{3} \cdot 5.9 \mathrm{SiO}_{2} \\
0.15 \mathrm{Na} \mathrm{O} \cdot 2.8 \mathrm{MgO} \cdot 2 \mathrm{CaO} \cdot 1.4 \mathrm{FeO} \cdot 0.2 \mathrm{Fe}_{2} \mathrm{O}_{3} \cdot 0.75 \mathrm{Al}_{2} \mathrm{O}_{3} \cdot 6.9 \mathrm{SiO}_{2} \\
0.7 \mathrm{MgO} \cdot 0.8 \mathrm{CaO} \cdot 0.3 \mathrm{FeO} \cdot 0.15 \mathrm{Al}_{2} \mathrm{O}_{3} \cdot 1.9 \mathrm{SiO}_{2}\end{array}$ \\
\hline $\begin{array}{l}\text { Halloysite } \\
\text { Ca-montmorillonite } \\
\text { MgCa-montmorillonite }\end{array}$ & $\begin{array}{l}\mathrm{Al}_{2} \mathrm{O}_{3} \cdot 2 \mathrm{SiO}_{2} \\
\mathrm{CaO} \cdot 7 \mathrm{Al}_{2} \mathrm{O}_{3} \cdot 22 \mathrm{SiO}_{2} \\
0.7 \mathrm{MgO} \cdot 0.35 \mathrm{CaO} \cdot 1.65 \mathrm{Al}_{2} \mathrm{O}_{3} \cdot 8 \mathrm{SiO}_{2}\end{array}$ \\
\hline $\begin{array}{l}\text { Vermiculite } \\
\text { Chlorite }\end{array}$ & $\begin{array}{l}5.5 \mathrm{MgO} \cdot 0.325 \mathrm{Fe}_{2} \mathrm{O}_{3} \cdot 1.5 \mathrm{Al}_{2} \mathrm{O}_{3} \cdot 5.6 \mathrm{SiO}_{2} \\
3.5 \mathrm{MgO} \cdot 1.5 \mathrm{FeO} \cdot \mathrm{Al}_{2} \mathrm{O}_{3} \cdot 3 \mathrm{SiO}_{2}\end{array}$ \\
\hline
\end{tabular}

Biotite composition derived from the chemical analyses given in Table 4. The other mineral compositions, partly simplified, are as given by Deer et al. [1962].

*Simplified, structural water omitted.

and $99.995 \%$, respectively. We fitted the data plotted in Figure 4 to a straight line using the mean absolute deviation minimizing method [Press et al., 1989], and we found the following relations:

$$
\begin{gathered}
{[\mathrm{Ca}]_{p}=-72.8+0.38 \times \text { pollution }} \\
{[\mathrm{Mg}]_{p}=81.4+0.3 \times \text { pollution }} \\
{[\mathrm{Na}]_{p}=11.9+0.32 \times \text { pollution }}
\end{gathered}
$$

where pollution $\equiv\left[\mathrm{Cl}^{-}\right]+\left[\mathrm{SO}_{4}^{2-}\right]+\left[\mathrm{NO}_{3}^{-}\right]$(all concentrations in microequivalents per liter).

The slopes of these lines $(0.38,0.30$, and 0.32 , respectively) represent the rates at which the $[X]_{p}$ concentrations increase. The high rate of increase of $[\mathrm{Na}]_{p}$ might be the result of contributions of domestic sewage and/or ion exchange reactions occurring in the soil in which $\mathrm{Ca}$ and $\mathrm{Mg}$ replace $\mathrm{Na}$ at exchange sites. The latter would mean that our working hypothesis of a steady state between the occupancy of the ex- change sites and the supply of cations in fertilizers is not fully warranted. Table 10 contains the median values of the measured concentrations and of the calculated concentrations attributed to weathering or pollution for all dissolved components. The appearance of negative values indicates that the component was used from the solution and incorporated in the secondary mineral. The predicted relative abundances of the clay minerals as well as the relative contribution of the weathering of plagioclase to the water composition are given in the bottom of Table 10 .

\section{General Interpretation of SiB Results}

The halloysite abundance predicted by the best-fit solutions presented in Table 10 (bottom) is very high for groups 2, 3, 4, $1,8,9$, and 5 (close to $100 \%$ ). For group 6 and group 10, waters with a mixture of halloysite and montmorillonite, rich in halloysite, is predicted as a result of the weathering of plagioclase. This mixture is produced by the combined reaction $0.9(\mathrm{R} 5)+$

\begin{tabular}{|c|c|c|}
\hline Reaction & Mineral & Weathering Reaction* \\
\hline (R1) & ite & 1.87 plagioclase $+x \mathrm{H}_{2} \mathrm{O}+2 \mathrm{CO}_{2} \rightarrow$ halloysite \\
\hline & & $\mathrm{SiO}_{3}^{\circ}$ \\
\hline & & $+2.15 \mathrm{H}_{2} \mathrm{SiO}_{3}^{\circ}$ \\
\hline & 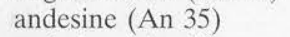 & $\mathrm{CO}_{2} \rightarrow$ halloysite $+0.96 \mathrm{Na}^{+}+0.52 \mathrm{Ca}^{2+}+$ \\
\hline & 40) & $2 \mathrm{CO}_{2} \rightarrow$ halloysite $+0.86 \mathrm{Na}^{+}+0.57 \mathrm{Ca}^{2+}+2 \mathrm{HCO}_{3}^{--}+1.71 \mathrm{H}_{2} \mathrm{SiO}_{3}^{\circ}$ \\
\hline & & $\begin{array}{l}2.36 \text { plagioclase }+x \mathrm{H}_{2} \mathrm{O}+1.2 \mathrm{CO}_{2}+0.7 \mathrm{Mg}^{2+}+1.87 \mathrm{H}_{2} \mathrm{SiO}_{3}^{\circ} \rightarrow \mathrm{MgCa} \text {-montmorillonite }+1.41 \\
\mathrm{Na}^{+}+0.59 \mathrm{Ca}^{2+}+1.2 \mathrm{HCO}_{3}^{-}\end{array}$ \\
\hline (R7) & biotite & $\begin{array}{l}0.67 \text { biotite }+x \mathrm{H}_{2} \mathrm{O}+4 \mathrm{CO}_{2}+0.35 \mathrm{O}_{2} \rightarrow \text { halloysite }+0.84 \mathrm{Fe}_{2} \mathrm{O}_{3}+0.2 \mathrm{TiO}_{2}+0.13 \mathrm{Na}^{+}+1.2 \\
\mathrm{~K}^{+}+1.33 \mathrm{Mg}^{2+}+4 \mathrm{HCO}_{3}^{-}+1.93 \mathrm{H}_{2} \mathrm{SiO}_{3}^{\circ}\end{array}$ \\
\hline (R8 & bi & $\begin{array}{l}\text { biotite }+x \mathrm{H}_{2} \mathrm{O}+5 \mathrm{HCO}_{3}^{-}+3.5 \mathrm{Mg}^{2+}+0.53 \mathrm{O}_{2} \rightarrow \text { vermiculite }+0.93 \mathrm{Fe}_{2} \mathrm{O}_{3}+0.3 \mathrm{TiO}_{2}+0.2 \\
\mathrm{Na}^{+}+1.8 \mathrm{~K}^{+}+5 \mathrm{CO}_{2}+0.3 \mathrm{H}_{2} \mathrm{SiO}_{3}^{\circ}\end{array}$ \\
\hline (R9) & hornblende & $\begin{array}{l}\text { 1.33 hornblende }+x \mathrm{H}_{2} \mathrm{O}+6.2 \mathrm{CO}_{2}+0.29 \mathrm{O}_{2} \rightarrow \text { chlorite }+0.77 \mathrm{Fe}_{2} \mathrm{O}_{3}+0.4 \mathrm{Na}^{+}+0.23 \mathrm{Mg}^{2+}+ \\
2.67 \mathrm{Ca}^{2+}+6.2 \mathrm{HCO}_{3}^{-}+6.2 \mathrm{H}_{2} \mathrm{SiO}_{3}^{\circ}\end{array}$ \\
\hline$(1$ & & $\begin{array}{l}2.2 \text { hornblende }+x \mathrm{H}_{2} \mathrm{O}+19.68 \mathrm{CO}_{2}+0.77 \mathrm{O}_{2} \rightarrow \mathrm{MgCa}^{2} \text {-montmorillonite }+1.98 \mathrm{Fe}_{2} \mathrm{O}_{3}+0.66 \mathrm{Na}^{+} \\
\quad+5.46 \mathrm{Mg}^{2+}+4.05 \mathrm{Ca}^{2+}+19.68 \mathrm{HCO}_{3}^{-}+7.18 \mathrm{H}_{2} \mathrm{SiO}_{3}^{\circ}\end{array}$ \\
\hline
\end{tabular}
0.1 (R6) (Table 10). In order to explain the chemistry of

Table 9. Extreme Weathering Reactions for Primary Minerals Given in Table 8

*Round-off coefficients. 
Table 10. Results Obtained With the SiB Algorithm

\begin{tabular}{|c|c|c|c|c|c|c|c|c|c|c|}
\hline \multirow{4}{*}{$\begin{array}{l}\text { Water group } \\
\text { Weathering reaction(s) }\end{array}$} & \multicolumn{10}{|c|}{ Unit } \\
\hline & \multirow{3}{*}{$\begin{array}{c}\gamma_{5}, \gamma_{8} \\
\begin{array}{c}2 \\
(\mathrm{R} 1)\end{array}\end{array}$} & \multirow{3}{*}{$\begin{array}{c}\gamma \Delta_{3} \\
3 \\
(\mathrm{R} 2), \\
(\mathrm{R} 7)\end{array}$} & \multicolumn{5}{|c|}{$\Delta_{0-2}$} & \multicolumn{3}{|c|}{ Amphibolites and Metadiabases } \\
\hline & & & 4 & 1 & 8 & 9 & 5 & & 10 & 6 \\
\hline & & & $\begin{array}{l}\text { (R2), } \\
\text { (R8) }\end{array}$ & $\begin{array}{l}\text { (R3), } \\
\text { (R8) }\end{array}$ & $\begin{array}{l}\text { (R4), } \\
(\mathrm{R} 8)\end{array}$ & $\begin{array}{l}\text { (R4), } \\
\text { (R7) }\end{array}$ & $\begin{array}{l}\text { (R5), } \\
(\mathrm{R} 7)\end{array}$ & 0.9 (R5) & + 0.1(R6), (R10) & $0.9(\mathrm{R} 5)+0.1(\mathrm{R} 6),(\mathrm{R} 10)$ \\
\hline$\left[\mathrm{Na}^{+}\right] 1$ & 236 & 250 & 294 & 305 & 252 & 305 & 336 & & 302 & 299 \\
\hline$\left[\mathrm{Na}^{+}\right] 2$ & 0 & 2 & 2 & 0 & 1 & 2 & 1 & & 3 & 17 \\
\hline$\left[\mathrm{Na}^{+}\right]_{p}$ & 65 & 129 & 123 & 117 & 312 & 169 & 319 & & 443 & 284 \\
\hline$\left[\mathrm{K}^{+}\right] 1$ & 0 & 0 & 0 & 0 & 0 & 0 & 0 & & 0 & 0 \\
\hline$\left[\mathrm{K}^{+}\right] 2$ & 0 & 18 & 19 & 1 & 10 & 15 & 6 & & 0 & 0 \\
\hline$\left[\mathrm{K}^{+}\right]_{p}$ & 17 & 6 & 8 & 31 & 15 & 14 & 24 & & 36 & 41 \\
\hline$\left[\mathrm{Mg}^{2+}\right] 1$ & 0 & 0 & 0 & 0 & 0 & 0 & 0 & & -46 & -46 \\
\hline$\left[\mathrm{Mg}^{2+}\right] 2$ & 0 & 39 & -73 & -5 & -37 & 33 & 13 & & 54 & 278 \\
\hline$\left[\mathrm{Mg}^{2+}\right]_{p}$ & 90 & 99 & 223 & 192 & 416 & 269 & 334 & & 496 & 192 \\
\hline$\left[\mathrm{Ca}^{2+}\right] 1$ & 36 & 125 & 147 & 262 & 271 & 328 & 448 & & 380 & 376 \\
\hline$\left[\mathrm{Ca}^{2+}\right] 2$ & 0 & 0 & 0 & 0 & 0 & 0 & 0 & & 40 & 206 \\
\hline$\left[\mathrm{Ca}^{2+}\right]_{p}$ & 44 & 67 & 109 & 30 & 357 & 105 & 168 & & 443 & 100 \\
\hline$\Sigma[X]_{r}{ }^{1 p}$ & 272 & 434 & 389 & 563 & 497 & 683 & 804 & & 733 & 1130 \\
\hline$\Sigma[X]_{p}$ & 216 & 301 & 463 & 370 & 1100 & 557 & 845 & & 1418 & 617 \\
\hline$[\mathrm{B}]$, & 252 & 433 & 382 & 579 & 497 & 606 & 720 & & 844 & 1135 \\
\hline$\left[\mathrm{Cl}^{-}\right]$, & 131 & 173 & 192 & 178 & 304 & 299 & 326 & & 553 & 266 \\
\hline$\left[\mathrm{SO}_{4}^{2-}\right]_{t}$ & 56 & 71 & 136 & 79 & 326 & 140 & 367 & & 422 & 136 \\
\hline$\left[\mathrm{NO}_{3}^{-}\right]_{t}$ & 51 & 44 & 140 & 53 & 472 & 153 & 150 & & 385 & 78 \\
\hline Pollution & 238 & 288 & 468 & 310 & 1102 & 592 & 843 & & 1360 & 480 \\
\hline $\operatorname{Err} R(\%)$ & 3.8 & 0.1 & 0.9 & -1.4 & 0.0 & 6.0 & 5.4 & & -7.0 & -0.2 \\
\hline $\operatorname{Err} P(\%)$ & -4.8 & 2.2 & -0.5 & 8.8 & -0.1 & -3.0 & 0.2 & & 2.1 & 12.5 \\
\hline$[\mathrm{Si}]_{,}$ & 472 & 534 & 591 & 610 & 506 & 615 & 676 & & 498 & 629 \\
\hline$[\mathrm{B}]_{t} /[\mathrm{Si}]_{t}$ & 0.53 & 0.81 & 0.65 & 0.95 & 0.98 & 0.99 & 1.07 & & 1.69 & 1.80 \\
\hline Halloysite, \% & 100.0 & 100 & 95.5 & 99.7 & 98.0 & 100.0 & 100 & & 88.7 & 83.5 \\
\hline Vermiculite, \% & $\cdots$ & 0.0 & 4.5 & 0.3 & 2.0 & 0.0 & 0.0 & & $\ldots$ & $\cdots$ \\
\hline Chlorite, $\%$ & $\cdots$ & $\ldots$ & $\ldots$ & $\cdots$ & $\cdots$ & $\cdots$ & $\cdots$ & & 0.0 & 0.0 \\
\hline MgCa-mon., $\%$ & $\cdots$ & $\cdots$ & $\cdots$ & $\cdots$ & $\cdots$ & $\cdots$ & $\cdots$ & & 11.3 & 16.5 \\
\hline Plagioclase, \% & 100.0 & 96.9 & 97.3 & 99.8 & 98.6 & 98.3 & 98.2 & & 97.9 & 89.9 \\
\hline
\end{tabular}

The groups analyzed were groups 1 to 10 . The chemistry of groups $1,2,3,4,5,6,8$, 9, and 10 can be explained using the SiB algorithm. The reactions valid for each group are presented in the third row; for groups 6 and 10 they are combined reactions of the extreme reactions given in Table 9. Here [ ] = concentrations of the dissolved components in microequivalents per liter for cations and anions, and in micromoles per liter for dissolved silica; $t$, total; $r$, chemical weathering; $p$, pollution; 1 and 2 , derived from weathering of the first and second primary mineral, respectively; $X=\mathrm{Na}^{+}, \mathrm{K}^{+}, \mathrm{Mg}^{2+}, \mathrm{Ca}^{2+}$. Pollution $=\left[\mathrm{Cl}^{-}\right]_{t}+\left[\mathrm{SO}_{4}^{2-}\right]_{t}+\left[\mathrm{NO}_{3}^{-}\right]_{t}$. ErrR $R(\%)$ and $\operatorname{Err} P(\%)$ are the relative deviations in the charge balances for bicarbonate (ErrR) and pollution (ErrP) calculated using (29) and (30), in Appendix 2.

groundwaters, Garrels [1967] also suggests that plagioclase alters to similar mixtures of secondary minerals.

Garrels [1967] used a plot of the $[\mathrm{B}]_{t} /[\mathrm{Si}]_{t}$ (mole ratio) versus $[\mathrm{B}]_{t}$ (milligrams per liter) to discriminate between waters related to different types of igneous rocks. In such plot groups 1 , $2,3,4,5,8$, and 9 are indeed characteristic of granitoid rocks, whereas groups 6 and 10 are characteristic of andesitic rocks.

\section{Detailed Interpretation of SiB Results}

In the following discussion we refer to the petrological information given in Figures $2 \mathrm{a}$ and $2 \mathrm{~b}$. On the basis of their chemical compositions (Table 1 ) we calculated $\mathrm{An}=3$ for the plagioclase in the $\gamma_{5}$ granite and $\mathrm{An}=7$ for the $\gamma_{8}$ granite. The composition of group 2 waters can be largely explained by chemical weathering of plagioclase (R1) in these rocks. Group 3 waters obtained their composition by a combination of weathering of plagioclase (R2) and biotite (R7) to halloysite.

According to Costa et al. [1971] the plagioclases in the $\Delta_{0-2}$ granitoids are strongly zonated (An 18 to An 37). On the basis of the CIPW results (Table 3 ) the average anorthite contents indicate a spatial range from An 8 to An 45 in plagioclases in the $\Delta_{0-2}$ units. These changes in the chemical composition of plagioclases are reflected in the chemistries of groups 4, 1, 8,9, and 5. Group 4 waters are related to chemical weathering (R2) of oligoclase (An 20), group 1 waters to chemical weathering
(R3) of oligoclase/andesine (An 30), group 8 and group 9 waters to chemical weathering (R4) of andesine (An 35), and group 5 waters to chemical weathering (R5) of andesine (An 40 ). For the groups related to rocks with more sodic plagioclase types (groups 1 and 4 ) biotite weathering leads to the formation of vermiculite (R8); for groups 9 and 5 biotite alters to halloysite (R7). Group 8 and group 9 waters are derived from weathering of the same plagioclase type, but group 8 waters are obviously more polluted, probably resulting in the production of vermiculite. Group 6 and group 10 waters, although collected in the central area, cannot be explained by a combination of the reactions (R2)-(R4) and (R7) and (R8). Instead, the chemistries of these groups can be explained by weathering of andesine (R5) + (R6) and of hornblende (R10). This means that these chemistries are related to the weathering of basic rocks present as dikes in the central area.

\section{Areal Distribution of the Groups}

The areal distribution of the waters of groups 2, 3, 4, 1, 8, 9, and 5 is shown in Figure $5 \mathrm{a}$. The distribution coincides rather well with the different petrological units (cf. Figures $2 \mathrm{a}$ and $2 \mathrm{~b}$ ). This is additional confirmation of the validity of the results. However, there seem to be some discrepancies. The group 2 waters are also present in the outer rim of the pluto- 


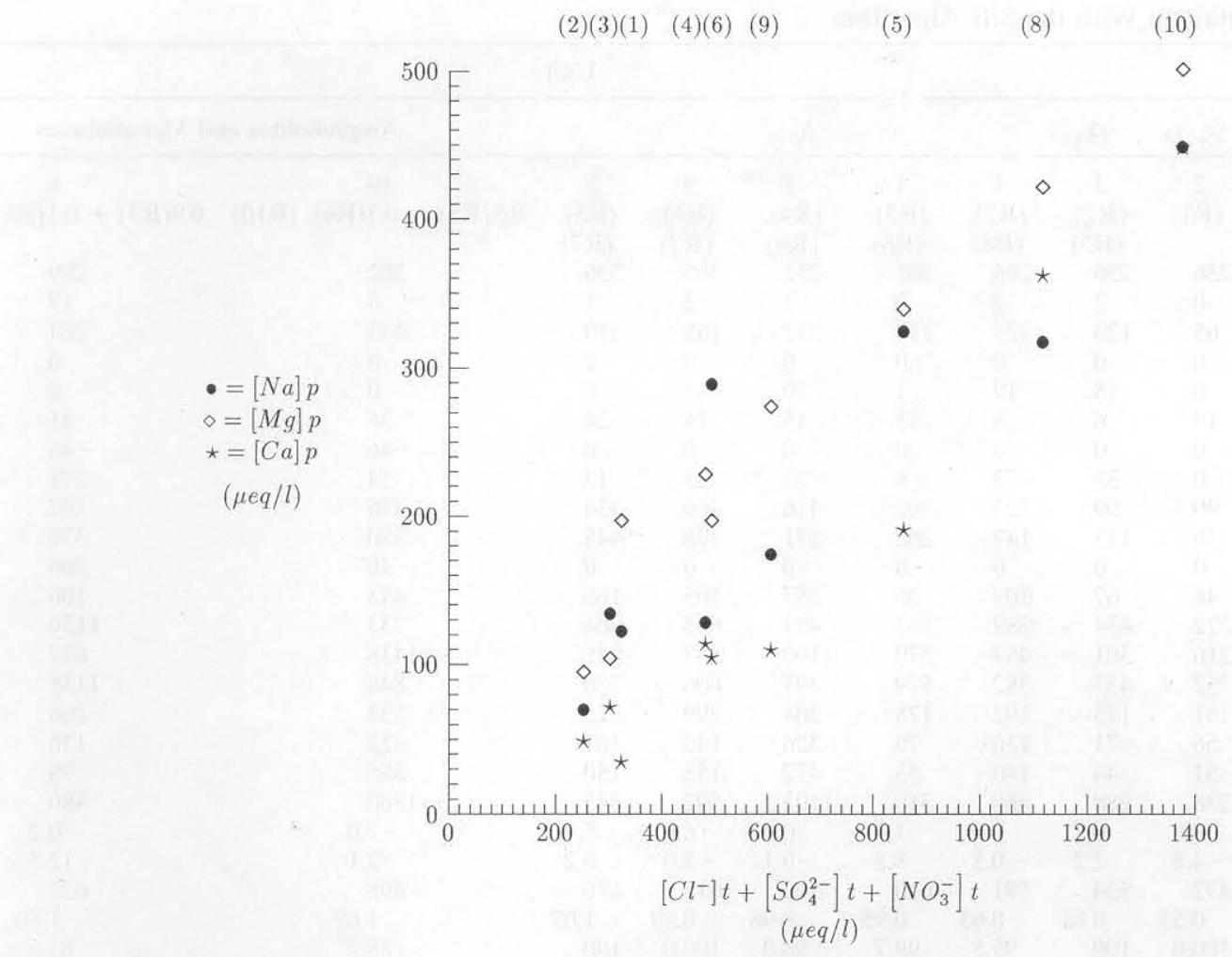

Figure 4. Plot of calculated median $\mathrm{Na}^{+}, \mathrm{Mg}^{2+}$, and $\mathrm{Ca}^{2+}$ concentrations attributed to pollution (p) against the sum of the median concentrations of $\mathrm{Cl}^{-}, \mathrm{NO}_{3}^{-}$, and $\mathrm{SO}_{4}^{2-}$. The numbers of the groups are shown in brackets at the top of this figure.

nite, between Fatela and Alcaide and southwest of Alcaide. We believe that these waters acquired their composition by interaction with schists, which is also suggested by the presence of a group 2 type of water near Souto da Casa, situated in schist terrain. Typically, group 2 waters are low in the $[\mathrm{Ca}]_{r} /[\mathrm{Na}]_{r}$ ratio, which is characteristic for the weatherable mineral content of the schists. Another discrepancy is the presence of group 3 waters in the central plutonite. Note, however, that group 3 waters reflect rather intense chemical weathering (biotite $\rightarrow$ halloysite) of oligoclase-containing granitoids. This is also possible in the central plutonite where composition of the zonated plagioclases varies from oligoclase to andesine and where the presence of dikes may permit deeper infiltration of meteoric water and/or a change in the lateral flow. Within the central area it is not possible to recognize any specific area for groups $4,1,8,9$, and 5 . This is consistent with the variability of the anorthite content of zonated plagioclase crystals.

The areal distribution of waters in groups 6 and 10 is shown in Figure $5 b$. It would be too optimistic to expect all sample locations to coincide exactly with the dikes shown on this map, but the figure does support a spatial relation between these waters and the dikes.

It is remarkable that we apparently could explain the water chemistries without taking into account lateral transport of groundwater. One would expect the composition of water that moves laterally from one petrological unit to another to retain and not to lose its inherited signature. It seems, however, that the overprint of the water-rock interactions in the new petrological environment is sufficiently strong to determine the water composition.

\section{Errors}

Ideally, when the median concentrations of the groups are expressed in the microequivalents per liter scale, $\Sigma[X]_{r}=[\mathrm{B}]_{t}$ and $\Sigma[X]_{p}=\left[\mathrm{Cl}^{-}\right]+\left[\mathrm{SO}_{4}^{2-}\right]+\left[\mathrm{NO}_{3}^{-}\right]$. ErrR and $\operatorname{Err} P$ (in percent) (Table 10) are measures of the deviations from ideality. These deviations increase when there are deviations from electroneutrality in the dataset and/or when the medians are not the best estimators of the average concentrations of the ions within a group. In all cases but one (group 6) the deviations are small and considered to be acceptable given the assumptions that had to be made. One should bear in mind that (1) average compositions of the parent minerals, which, especially in the case of the mafic minerals, may not represent the true compositions of the minerals actually being weathered, and that (2) compositions of the weathering products may not exactly represent the compositions of the minerals actually being formed; this holds especially for the smectites, for there is a lack of data on their abundance in the area and their composition.

Our case is basically not different from any other weathering study: the more one knows about abundances and compositions of primary and secondary minerals, the better one can model the water-rock interactions. In our case the extra complicating factor is the relatively high contribution made by other sources, together called "pollution," which causes a poor signal-to-noise ratio.

\section{Anomalous Samples}

In the foregoing we showed that we could distinguish the dominant water-rock interactions in the Fundão area, which is 

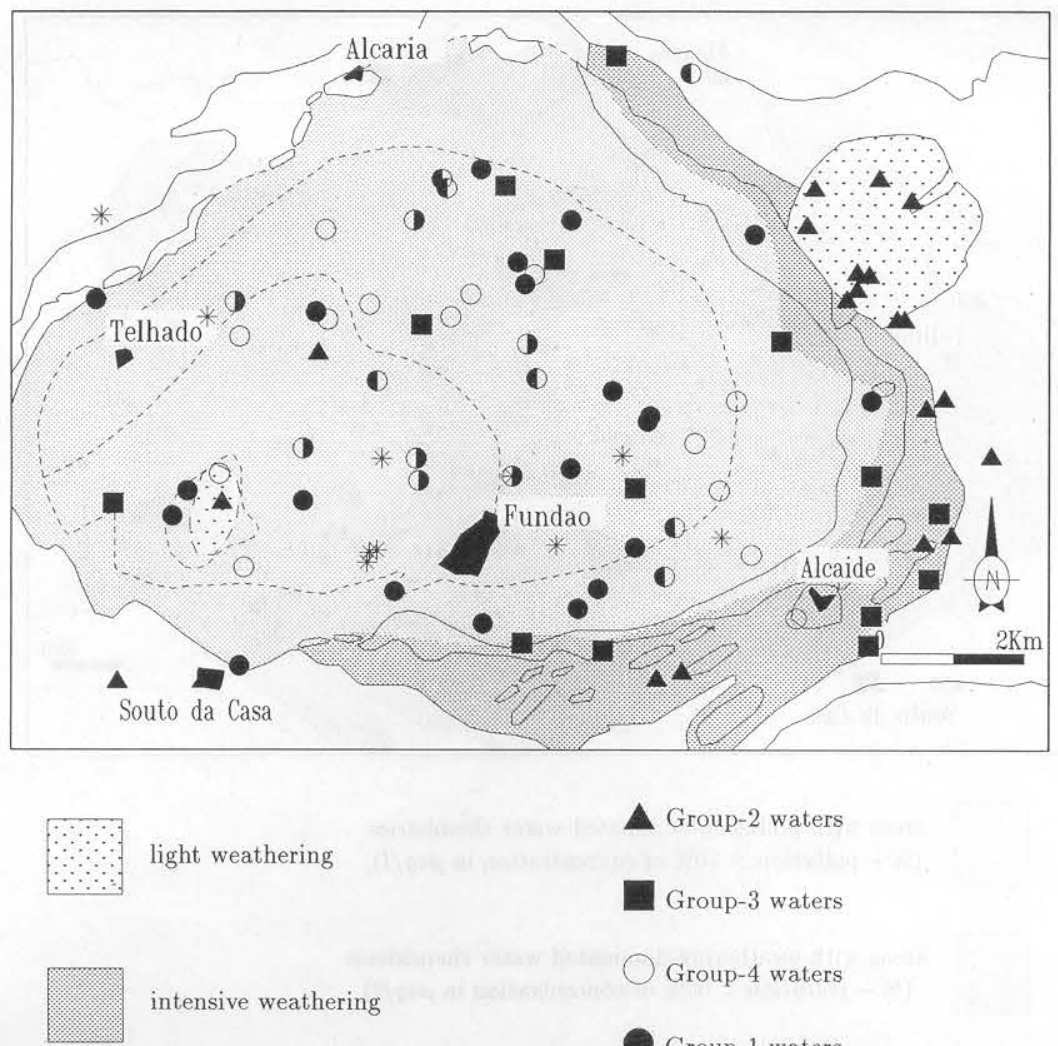

light weathering

A Group-2 waters

(1)

Group-3 waters

intensive weathering

Group-4 waters

Group-1 waters

( Group-8 waters

moderate to intensive weathering

(1) Group-9 waters

* Group-5 waters

Figure 5a. Waters related to the major rocks in the Fundão area (groups 1 to 5, 8, and 9).

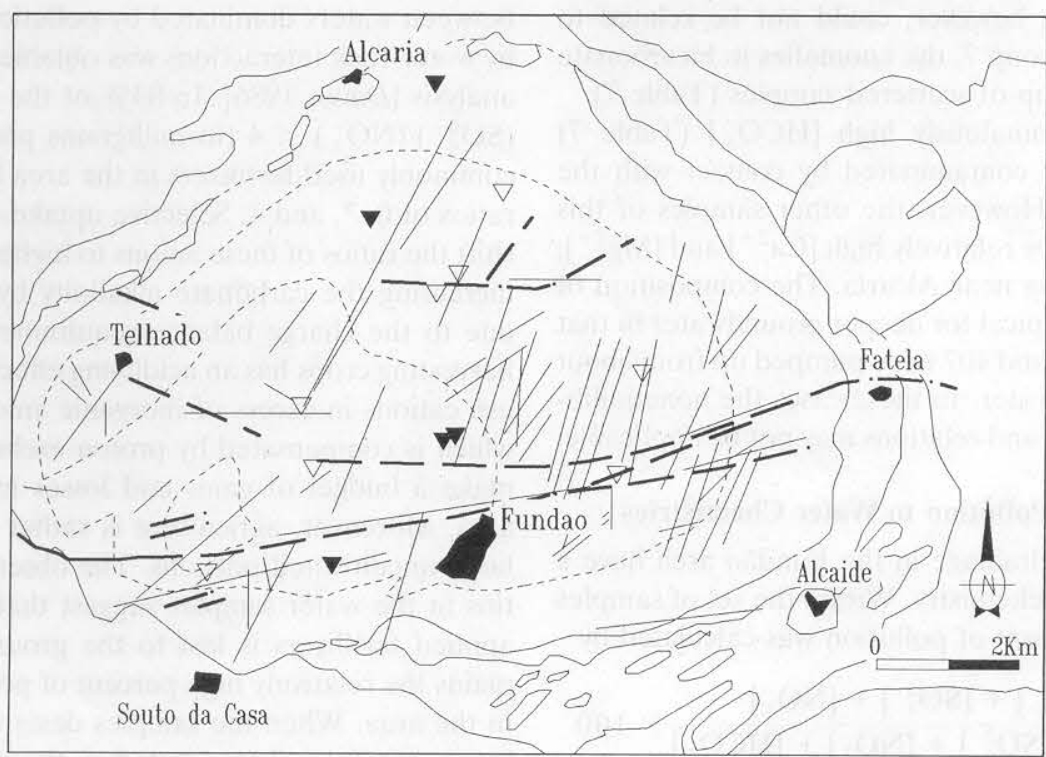

Group-10 waters

$\nabla$ Group-6 waters

Figure 5b. Waters related to the structures in the Fundão area (groups 6 and 10). 

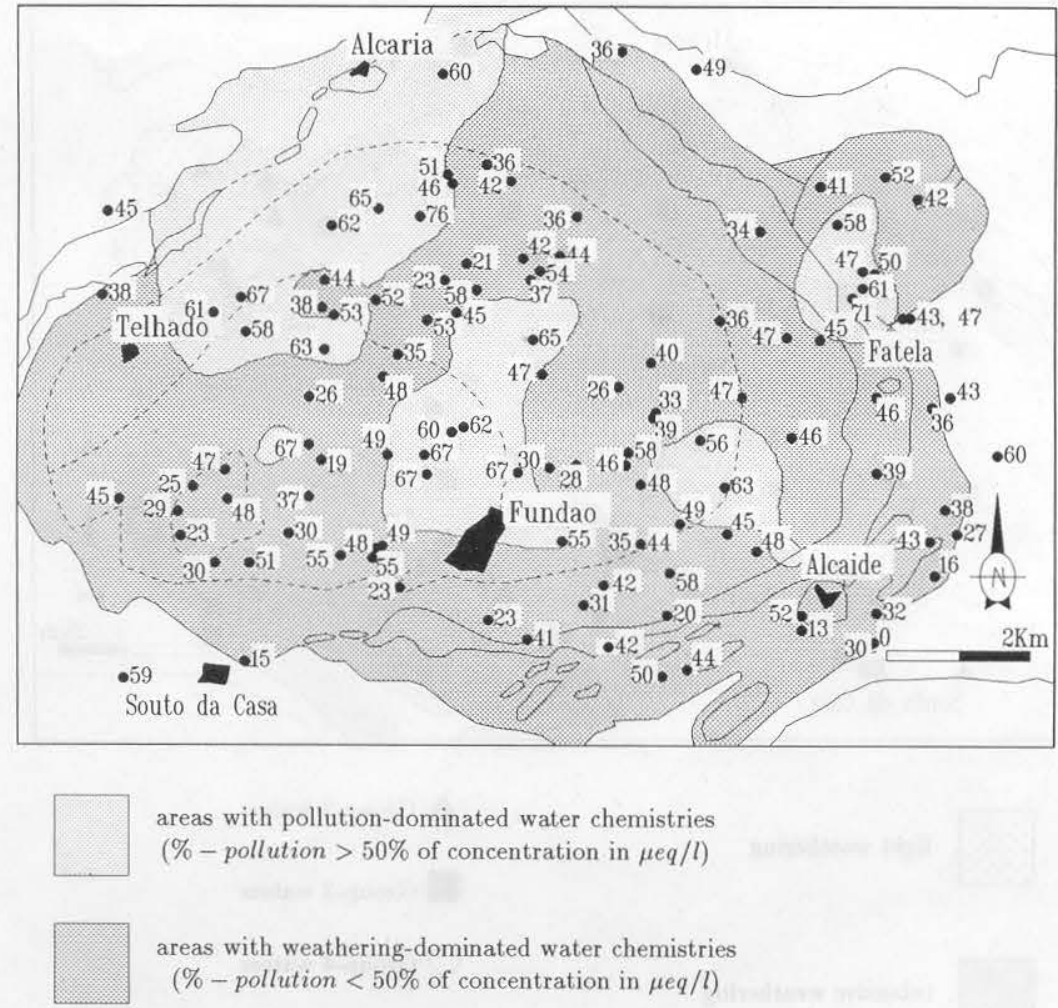

Figure 6. The influence of airborne and anthropogenic input on the chemistry of waters in the Fundão area. The numbers shown for individual samples are the values (in percent) of the ratio $\Sigma[$ anions $] /(\Sigma[$ anions] + $\left[\mathrm{HCO}^{-}\right]$), where $\Sigma$ anions $]=\left[\mathrm{Cl}^{-}\right]+\left[\mathrm{NO}_{3}^{-}\right]+\left[\mathrm{SO}_{4}^{2-}\right]$ (in microequivalents per liter). The contours separating the light and dark shaded areas are drawn for $50 \%$ values of that ratio. The composition of waters in the dark shaded areas is dominated by water-rock interaction, the composition of water in the light shaded area is dominated by pollution.

complicated with respect to petrology and pollution. Some groups of water samples, however, could not be related to water-rock interactions: group 7 , the anomalies in bicarbonate and pollutants, and a group of scattered samples (Table 7).

Of the group with anomalously high $\left[\mathrm{HCO}_{3}^{-}\right]$(Table 7) sample 218 was probably contaminated by contact with the cement wall of the well. However, the other samples of this group, also characterized by relatively high $\left[\mathrm{Ca}^{2+}\right]$ and $\left[\mathrm{Mg}^{2+}\right]$, are from the northern area near Alcaria. The composition of these waters is probably typical for deeper groundwater in that area because samples 220 and 407 were pumped up from about $10 \mathrm{~m}$ for use as drinking water. In these cases the nonequilibrium weathering reactions and relations may not be applicable.

\section{Relative Contribution of Pollution to Water Chemistries}

Fertilizers and sewage drainage in the Fundão area have a large impact on the water chemistry. Within the set of samples in groups 1 to 10 the percent of pollution was calculated by

$$
\% \text { pollution }=\frac{\left[\mathrm{Cl}^{-}\right]+\left[\mathrm{SO}_{4}^{2-}\right]+\left[\mathrm{NO}_{3}^{-}\right]}{\left[\mathrm{Cl}^{-}\right]+\left[\mathrm{SO}_{4}^{2-}\right]+\left[\mathrm{NO}_{3}^{-}\right]+\left[\mathrm{HCO}_{3}^{-}\right]} \times 100
$$

where the anion concentrations are in microequivalents per liter.

It has already been mentioned that the input of atmospheric salts is included in this definition of pollution. The results are shown in Figure 6. Contours between light and dark areas represent the $50 \%$ pollution values. An identical separation between waters dominated by pollution and those dominated by water-rock interactions was obtained using correspondence analysis [Davis, 1986]. In $83 \%$ of the 160 water samples $0<$ $\left(\mathrm{SO}_{4}^{2-}\right) /\left(\mathrm{NO}_{3}^{-}\right)<4$ (in milligrams per liter). The three most commonly used fertilizers in the area have $\mathrm{SO}_{4}^{2-} / \mathrm{NO}_{3}^{-}$weight ratios of 0,3 , and 4 . Selective uptake of $\mathrm{NO}_{3}^{-}$by crops would shift the ratios of these anions to higher values, simultaneously increasing the carbonate alkalinity by an equivalent amount due to the charge balance requirement. On the other hand, harvesting crops has an acidifying effect on soils because plants use cations in excess of inorganic anions from the soil water, which is compensated by proton exchange. It is impossible to make a budget of gains and losses in alkalinity in the study area. Moreover, agriculture is rather patchy in an area with large uncultivated portions. The observed sulphate/nitrate ratios in the water samples suggest that a large fraction of the applied fertilizers is lost to the groundwater, which also explains the relatively high percent of pollution in water samples in the area. When the samples designated as anomalies (pollutants) in Table 7 are plotted on the map (Figure 6), one finds in all cases but one that these samples were indeed collected in the lightly shaded area. These samples have scores between 70 and $93 \%$ pollution, and they were not included in groups 1 to 10 because the characteristics of water-rock interaction are swamped by the anthropogenic contributions. 


\section{Scattered Samples}

No attempt has been made to clarify the chemistry of the remaining groups of samples. This would have to be done on a sample-by-sample basis and would require more detailed information about the hydrology than is currently available. Given the purpose of this study, the results are satisfying, since they explain the water chemistries in this complicated area in the great majority of cases.

\section{Conclusions}

The RST algorithm that was developed to distinguish groups of water samples with similar chemical characteristics is very effective. The application of the $\mathrm{SiB}$ algorithm to relate water compositions of the identified groups to weathering reactions likely to occur in the Fundão area produced promising and mostly convincing results. With the help of this $\mathrm{SiB}$ methodology we were able to relate water types with various granitic units in the area and also to basic dikes. This is a remarkable result for an area where anthropogenic contributions to the water chemistry are relatively very high. It should be possible to improve the results when more detailed knowledge is collected about the composition of the primary minerals in the various petrological units, about the abundance and composition of the secondary minerals formed by chemical weathering, and about the field relations between dikes and sites where samples of spring and well waters were collected.

\section{Appendix 1: RST Algorithm}

The initial raw data consist of a matrix $M_{N_{p}}$, where $N$ is the total number of water samples and $p$ the total number of numerical variables in each water sample. The $p$ variables used in the present case are $\mathrm{Na}^{+}, \mathrm{K}^{+}, \mathrm{Mg}^{2+}, \mathrm{Ca}^{2+}, \mathrm{HCO}_{3}^{-}, \mathrm{Cl}^{-}$, $\mathrm{SO}_{4}^{2-}$, and $\mathrm{NO}_{3}^{-}$.

\section{Stepwise Description of the Algorithm}

The RST algorithm comprises three main consecutive steps.

Step 1. The relation between two samples $i$ and $j$ is determined by a measure of similarity, $S_{i j}$, defined by

$$
S_{i j}=1 /\left(1+d_{i j}\right)
$$

where

$d_{i j}$ euclidian distance between two points, equal to $\left[\sum_{k=1}^{P} w_{k}\left(M_{i k}-M_{j k}\right)^{2}\right]^{1 / 2}$;

$M_{i k}, M_{j k}$ values for the variable $k$ in samples $i$ and $j$;

$p$ number of variables;

$w_{k}$ weight factor of variable $k$.

Step 2. In this step the $S_{i j}$ 's of each water sample are separated into $S_{i j}=1$ for the related samples and $S_{i j}=0$ for the unrelated samples. We adopted the following terminology used in signal processing theory: raw signal, the $N-1 S_{i j}$ 's of each sample sorted in ascending order; noise, a function that describes the values of the $S_{i j}$ 's for the unrelated samples; true signal, the $x S_{i j}$ 's that will be set to $S_{i j}=1$ (the relevant relations); and filter, the method by which the true signals are separated from the noise. The filtering method consists of the substeps 2.1 to 2.3 .

2.1: The $N-1$ relations are ranked in ascending order of their similarity to $i$, and this row forms the raw signal of sample $i$. The sample $j$ in position $m$ on the raw signal is identified as $\operatorname{samp}_{m}\left(j=\operatorname{samp}_{m}\right)$.
2.2: The first half of the population (lowest relations) is used to define a noise function:

$$
\text { noise }_{m}=\text { raw signal }_{m} \quad \text { if } m \leq N / 2
$$

otherwise

noise $_{m}=$ raw signal $_{N-m} \quad m=1,2,3, \cdots, N-1$

It is assumed that at least half of the lowest $S_{i j}$ 's of each sample may not be transformed into relevant relations. By this method no group may have more than $N / 2$ elements.

2.3: Now a binary square matrix, the relevant matrix $R_{N \times N}$, can be defined that represents the relevant relations of the samples. The line $i$ of the matrix $R$ (the true signal of sample $i$ ) is constructed by setting $R_{i j} \equiv 1$ for a relevant relation between $i$ and $j$, and $R_{i j} \equiv 0$ otherwise. For computation of the $R_{i j}$ 's the following filter was defined:

$$
R_{i j}=\text { nearest integer }\left\{\frac{\text { raw signal }_{m}-\text { noise }_{m}}{\text { raw signal }_{m}}\right\}
$$

where $m=1,2,3, \cdots, N-1$ and $j=$ samp $_{m}$.

Step 3. The previous steps do not guarantee the symmetry and transitivity of the relevant relations. The method of selection of the equivalent (symmetric and transitive) relations among the relevant relations identified in the foregoing step is described in the consecutive substeps 3.1 to 3.9 .

3.1: The symmetric relations are identified and saved in the elements above the main diagonal of $R$ :

$$
R_{i j}=R_{i j} \times R_{j i}
$$

where $i=1, \cdots, N-1$ and $j=i+1, \cdots, N$.

3.2: The transitive relations are identified. At the start of the transitivity test all samples have a status $R_{i i}=1$ (ungrouped). This status changes to $R_{i i}=0$ when sample $i$ is included in one group. Only the first element of each group remains with its status unaltered.

3.3: $\quad$ To begin a group one looks for a sample $i$ with $R_{i i}=$ 1.

3.4: For this sample $i$ one considers the elements $j$ ( $j=$ $i+1, \cdots, N)$ with $R_{i j}=1$.

3.5: For each sample $j$ the value of $R_{j j}$ is tested to check whether $j$ has already been included in another group. If $R_{j j}=$ 0 (which means that sample $j$ already belongs to another group), we assign $R_{i j}=0$ to guarantee that sample $j$ will not be grouped with sample $i$; otherwise sample $j$ is grouped with sample $i ; R_{i j}$ maintains the value 1 and $R_{j j}$ is set to 0 . Testing the remaining samples $k$, one continues to preserve the transitivity between samples $i, j$, and $k$ by

$$
R_{i k}=R_{i k} \times R_{j k}
$$

where $k=j+1, \cdots, N$.

3.6: In case not all samples $j$ with $R_{i j}=1$ are tested, the procedure starts again at step 3.4.

3.7: The group initiated in step 3.3 is now complete. All samples $j$ of row $i$ with $R_{i j}=1$ belong to it, and they have $R_{j j}$ $=0$, whereas $R_{i i}=1$.

3.8: $\quad$ This procedure must be completed for all samples $i$ which kept $R_{i i}=1$. Subsequently, another group is initiated, starting with step 3.3 , and run until $i=N$.

3.9: The elements of each group are listed. The total number of rows $i$ with $R_{i i}=1$ defines the number of groups that 
have been identified. Each group comprises samples $j$ of the rows with $R_{i j}=1$.

\section{Additional Remarks}

The following remarks regarding this method are due.

1. The transformation of the data by the use of the euclidian distance (step 1) is scale variant, so different results may be obtained when one changes the scale in which the data are expressed. This may seem to reduce the applicability of the method, but the most common partitioning methods all use scale variant measures of similarities or distances to produce the clustering [Kaufman and Rousseeuw, 1990].

2. When the number of groups generated in this procedure is quite large, no sample is likely to have more than $N / 2$ relevant relations (step 2 ), in which case no relevant relations are lost.

3. The results of the procedure described in steps 3.3 to 3.8 may, in some cases, depend on the order in which the operations are carried out. This is the case when the data set contains samples that may belong to different but similar groups.

\section{Appendix 2: SiB Algorithm}

\section{Stoichiometric Relations}

Considering the weathering of a primary silicate mineral $M$ into a combination of two secondary silicates $P_{1}$ and $P_{2}$, we can write a symbolic reaction:

$$
c_{M} M+\Sigma_{c}\left(c_{y} Y\right) \rightarrow c_{1} P_{1}+c_{2} P_{2}+\Sigma_{r}\left(c_{y} Y\right)
$$

This reaction represents the process by which $c_{M}$ moles of $M$ are converted into $c_{1}$ moles of $P_{1}$ and $c_{2}$ moles of $P_{2}, \Sigma_{c}\left(c_{y} Y\right)$ represents the number of moles of dissolved components consumed by the reaction, and $\Sigma_{r}\left(c_{y} Y\right)$ the number of moles released. When a component $Y$ is consumed, its source is, in the majority of the cases, weathering of other primary minerals, although $Y$ may also be provided by pollution.

The proportions in which $P_{1}$ and $P_{2}$ are formed are given by the $c_{1}$ and $c_{2}$ coefficients. For the use in the $\mathrm{SiB}$ algorithm a relation between $c_{1}$ and $c_{2}$ is established by

$$
c_{2}=1-c_{1}
$$

where $0 \leq c_{1} \leq 1$. The values of the $c_{M}$ and $c_{y}$ coefficients are dependent upon the values given to $c_{1}$ and $c_{2}$ as well as upon the chemical compositions of the primary mineral $M$ and the weathering products $P_{1}$ and $P_{2}$.

\section{Incongruent Reactions}

The major and minor oxides present in the structure of many silicate minerals are $\mathrm{Na}_{2} \mathrm{O}, \mathrm{K}_{2} \mathrm{O}, \mathrm{MgO}, \mathrm{CaO}, \mathrm{SiO}_{2}, \mathrm{TiO}_{2}$, $\mathrm{Al}_{2} \mathrm{O}_{3}, \mathrm{Fe}_{2} \mathrm{O}_{3}, \mathrm{FeO}$, and $\mathrm{MnO}$. The last five oxides are considered to be immobile oxides because their solubility in oxygenated water is very low when compared to the solubility of the first five oxides. The $\mathrm{SiB}$ algorithm assumes incongruent weathering, in which all $\mathrm{Al}_{2} \mathrm{O}_{3}$ is transferred from the structure of the primary minerals to the structure of the weathering products. Similar assumptions were made by Tardy [1971].

\section{Calculation of Reaction Coefficients}

The conservation of $\mathrm{Al}_{2} \mathrm{O}_{3}$ in the structure of the minerals can be used to define general equations for the $c_{M}$ and $c_{y}$ coefficients.

If $\alpha_{(o x)} m$ is the coefficient of oxide $o x$ in the structural formula of a mineral $m$ (either $M$ or $P$ ) then $c_{M}$ can be calculated by

$$
c_{M}=\frac{c_{1} \alpha_{\left(\mathrm{Al}_{2} \mathrm{O}_{3}\right)} P_{1}+c_{2} \alpha_{\left(\mathrm{Al}_{2} \mathrm{O}_{3}\right)} P_{2}}{\alpha_{\left(\mathrm{Al}_{2} \mathrm{O}_{3}\right)} M}
$$

where $c_{M} \alpha_{\left(\mathrm{Al}_{2} \mathrm{O}_{3}\right)} M$ represents the number of moles of $\mathrm{Al}_{2} \mathrm{O}_{3}$ needed to convert $c_{M}$ moles of $M$ into $c_{1}$ moles of $P_{1}$ and $c_{2}$ moles of $P_{2}$ and $\alpha_{\left(\mathrm{Al}_{2} \mathrm{O}_{3}\right)} P_{1}$ and $\alpha_{\left(\mathrm{Al}_{2} \mathrm{O}_{3}\right)} P_{2}$ are the number of moles of $\mathrm{Al}_{2} \mathrm{O}_{3}$ present in each mole of $P_{1}$ and $P_{2}$, respectively.

The $c_{y}$ coefficients are then given by

$$
\begin{aligned}
c_{\mathrm{Na}} & =2\left(c_{M} \alpha_{\left(\mathrm{Na}_{2} \mathrm{O}\right)} M-c_{1} \alpha_{\left(\mathrm{Na}_{2} \mathrm{O}\right)} P_{1}-c_{2} \alpha_{\left(\mathrm{Na}_{2} \mathrm{O}\right)} P_{2}\right) \\
c_{\mathrm{K}} & =2\left(c_{M} \alpha_{\left(\mathrm{K}_{2} \mathrm{O}\right)} M-c_{1} \alpha_{\left(\mathrm{K}_{2} \mathrm{O}\right)} P_{1}-c_{2} \alpha_{\left(\mathrm{K}_{2} \mathrm{O}\right)} P_{2}\right) \\
c_{\mathrm{Mg}} & =c_{M} \alpha_{(\mathrm{MgO})} M-c_{1} \alpha_{(\mathrm{MgO})} P_{1}-c_{2} \alpha_{(\mathrm{MgO})} P_{2} \\
c_{\mathrm{Ca}} & =c_{M} \alpha_{(\mathrm{CaO})} M-c_{1} \alpha_{(\mathrm{CaO})} P_{1}-c_{2} \alpha_{(\mathrm{CaO})} P_{2} \\
c_{\mathrm{H}_{2} \mathrm{SiO}_{3}} & =c_{M} \alpha_{\left(\mathrm{SiO}_{2}\right)} M-c_{1} \alpha_{\left(\mathrm{SiO}_{2}\right)} P_{1}-c_{2} \alpha_{\left(\mathrm{SiO}_{2}\right)} P_{2} \\
c_{\mathrm{HCO}_{3}} & =c_{\mathrm{Na}}+c_{\mathrm{K}}+2 c_{\mathrm{Mg}}+2 c_{\mathrm{Ca}}
\end{aligned}
$$

The equation for the bicarbonate coefficient (equation (14)) balances the symbolic equation for the ionic charge. The signs of these $c_{y}$ values indicate production or consumption of $Y$. If a $c_{y}$ coefficient is negative, then component $Y$ is consumed during the reaction; if $c_{y}$ is positive, then component $Y$ is released; if $c_{y}=0$, then component $Y$ is not involved in the weathering process.

\section{Water Chemistries}

The $\mathrm{SiB}$ algorithm is based on the assumption that the natural water chemistry may be largely explained by the weathering of one or two silicates. In the case of the weathering of two silicates, $M_{1}$ and $M_{2}$, the produced concentrations are

$$
\left[\mathrm{HCO}_{3}^{-}\right]_{t},\left[\mathrm{H}_{2} \mathrm{SiO}_{3}^{\circ}\right]_{t},[X]_{,}
$$

and the concentrations from pollution are

$$
\left[\mathrm{Cl}^{-}\right]_{t},\left[\mathrm{SO}_{4}^{2-}\right]_{t},\left[\mathrm{NO}_{3}^{-}\right]_{t},[X]_{p}
$$

where $X=\mathrm{Na}^{+}, \mathrm{K}^{+}, \mathrm{Mg}^{2+}, \mathrm{Ca}^{2+}$ and $t, r$, and $p$ are total, water-rock interaction, and pollution, respectively.

The following equations apply:

$$
\begin{aligned}
& {[X]_{r}=[X]_{1}+[X]_{2}} \\
& {[X]_{p}=[X]_{t}-[X]_{r}}
\end{aligned}
$$

where

$[X]$, molar concentration of $X$ (measured);

$[X]_{r}$ molar concentration of $X$ due to weathering;

$[X]_{p}$ molar concentration from pollution;

$[X]_{1,2}$ molar concentrations produced by weathering of minerals $M_{1}$ and $M_{2}$, respectively.

If we consider the weathering of only one primary mineral, the concentrations with subscript 2 are set to zero.

The purpose of the $\mathrm{SiB}$ algorithm is to calculate $[X]_{1},[X]_{2}$ and $[X]_{p}$ for all the cations. The molar mass balance equations for dissolved silica and bicarbonate are

$$
\begin{aligned}
& r_{\mathrm{Si}\left(M_{1}\right)}\left[M_{1}\right]+r_{\mathrm{Si}\left(M_{2}\right)}\left[M_{2}\right]=[\mathrm{Si}]_{t} \\
& r_{\mathrm{B}\left(M_{1}\right)}\left[M_{1}\right]+r_{\mathrm{B}\left(M_{2}\right)}\left[M_{2}\right]=[\mathrm{B}]_{t}
\end{aligned}
$$


where $\mathrm{Si}=\mathrm{H}_{2} \mathrm{SiO}_{3}^{\circ}, \mathrm{B}=\mathrm{HCO}_{3}^{-}, r_{\mathrm{Si}(M)}$ is the ratio between the stoichiometric coefficients of dissolved silica $\left(\mathrm{c}_{\mathrm{H}_{2} \mathrm{SiO}_{3}}\right.$, equation (13)) and of the minerals $M\left(c_{M}\right.$, equation (8)), $r_{\mathrm{B}(M)}$ is the ratio between the stoichiometric coefficients of dissolved bicarbonate $\left(\mathrm{c}_{\mathrm{HCO}_{3}}\right.$, equation (14)) and of the minerals $M\left(c_{M}\right.$, equation (8)), and $\left[M_{1}\right],\left[M_{2}\right]$ is the number of moles of $M_{1}$ and $M_{2}$ producing $[\mathrm{Si}]_{t}$ and $[\mathrm{B}]_{t}$, given in moles per liter.

Equations (17) and (18) connect the stoichiometric relations of the components, as predicted by the weathering reactions of $M_{1}$ and $M_{2}$ with the real composition of a given water sample. Writing the previous equations in matrix form we have

$$
\left[\begin{array}{ll}
r_{\mathrm{Si}\left(M_{1}\right)} & r_{\mathrm{Si}\left(M_{2}\right)} \\
r_{\mathrm{B}\left(M_{1}\right)} & r_{\mathrm{B}\left(M_{2}\right)}
\end{array}\right]\left[\begin{array}{l}
{\left[M_{1}\right]} \\
{\left[M_{2}\right]}
\end{array}\right]=\left[\begin{array}{l}
{[\mathrm{Si}]_{t}} \\
{[\mathrm{~B}]_{t}}
\end{array}\right]
$$

which can be solved for $\left[M_{1}\right]$ and $\left[M_{2}\right]$.

The concentrations of the cations produced during chemical weathering are then calculated by

$$
\begin{aligned}
& {[X]_{1}=r_{X\left(M_{1}\right)}\left[M_{1}\right]} \\
& {[X]_{2}=r_{X\left(M_{2}\right)}\left[M_{2}\right]}
\end{aligned}
$$

where $X$ represents one of the major cations. Then we use (15) and (16) to obtain the concentrations of cations related to pollution.

\section{Solids Consumed and Produced}

The percentage to which each mineral is used in the weathering process can be computed by

$$
\begin{gathered}
\%\left(M_{1}\right)=\frac{\left[M_{1}\right]}{\left[M_{1}\right]+\left[M_{2}\right]} \times 100 \\
\%\left(M_{2}\right)=100-\%\left(M_{1}\right)
\end{gathered}
$$

The number of moles of weathering products can also be calculated:

$$
\begin{aligned}
& {\left[P_{11}\right]=r_{c 11\left(M_{1}\right)}\left[M_{1}\right]} \\
& {\left[P_{12}\right]=r_{c 12\left(M_{1}\right)}\left[M_{1}\right]} \\
& {\left[P_{21}\right]=r_{c 21\left(M_{2}\right)}\left[M_{2}\right]} \\
& {\left[P_{22}\right]=r_{c 22\left(M_{2}\right)}\left[M_{2}\right]}
\end{aligned}
$$

where $\left[P_{11}\right],\left[P_{12}\right]$ are the number of moles of $P_{11}$ and $P_{12}$ produced in weathering of $\left[M_{1}\right]$ moles of $M_{1},\left[P_{21}\right],\left[P_{22}\right]$ are number of moles of $P_{21}$ and $P_{22}$ produced in weathering of $\left[M_{2}\right]$ moles of $M_{2} ; r_{c 11\left(M_{1}\right)}, r_{c 22\left(M_{1}\right)}$ are ratios of the stoichiometric coefficients of $P_{11}$ and $M_{1}$ and of $P_{12}$ and $M_{1}$ (equations (7) and (8)), and $r_{c 21\left(M_{2}\right)}, r_{c 22\left(M_{2}\right)}$ are ratios of the stoichiometric coefficients of $P_{21}$ and $M_{2}$ and of $P_{22}$ and $M_{2}$ (equations (7) and (8)). The relative abundance of each clay mineral with respect to the other clay minerals may be computed using equations similar to (22) and (23).

The solution is straightforward if chemical weathering affects only one mineral $M$. We can write the molar mass balance for silica by

$$
r_{\mathrm{Si} M}[M]=[\mathrm{Si}]_{t}
$$

which immediately gives

$$
[M]=[\mathrm{Si}]_{r} / r_{\mathrm{Si}(M)}
$$

The other concentrations and mole fractions are then calculated exactly as in the previous situation.

\section{Combining Results Obtained With the RST and SiB Algorithms}

In principle, the $\mathrm{SiB}$ algorithm can be applied to groups found by other clustering techniques as well. But the success depends on how well the groups represent waters with similar chemistries. The groups identified by the RST algorithm will have similar chemistries. In order to know how these chemistries are related to chemical weathering we have to attribute the average compositions of the groups to envisaged weathering reactions. This is done in the following manner.

1. By using (15), (16), and (19)-(24), we can calculate, for each sample in the group, the natural and pollution-derived concentrations of each cation, the number of moles of the primary and secondary minerals involved in the envisaged weathering reactions, and, in the case of weathering of just one mineral, the charge balance deviations (see equations (29) and (30)).

2. Median values are calculated of each of those concentrations, of each of the number of moles of primary and secondary minerals, and of each of the charge balance deviations. Since medians are robust estimators [Press et al., 1989], these single values are considered to be representative for the whole group.

\section{Additional Criteria}

When we apply the $\mathrm{SiB}$ algorithm to the median water composition of a group, using a specific set of weathering reactions, we need to test whether or not that group is related to those reactions. The following criteria have to be satisfied simultaneously.

1. With respect to the water composition, first, the natural concentrations of a given component $Y$ must have a positive sign when the weathering reactions predict the release of such component $\left(c_{y}>0\right)$, and they must have a negative sign when consumption of $Y$ is expected during the weathering process $\left(c_{y}<0\right)$. This check is made as follows: after calculation of median $[X]_{1}$ and $[X]_{2}$ for all the cations we compare the signs of those values with the signs of the corresponding stoichiometric coefficients $c$ (equations (9)-(12)); if they are equal for all the cations, then the group is related to the predefined set of weathering reactions; otherwise the group has to be tested with an other set of weathering reactions. Second, all the median pollution concentrations must be positive.

2. With respect to the weathering products, the median relative abundances of the weathering products, predicted by the $\mathrm{SiB}$ algorithm (equations (24a)-(24d)) should be in agreement with the real abundances in the area in which the water samples were collected. The results cannot often be checked against this criterion because the relative abundances of the weathering products are poorly known or not known at all. In those cases the $\mathrm{SiB}$ algorithm is only capable of giving sets of possible results which meet the requirements with respect to the water composition.

3. If we have only one mineral, we will have to satisfy the previous criteria as well as the charge balances. We only use the molar mass balance of dissolved silica (equation (25)), and for that reason the charge balances are not guaranteed. We consider that a given group is related to the weathering of one mineral if the median deviations of the charge balances for bicarbonate and pollution are less than $10 \%$ of the total ionic charge. Charge balance equations for bicarbonate and pollution are given by 


$$
\begin{gathered}
\Sigma z_{X}[X]_{r}=\left[\mathrm{HCO}_{3}^{-}\right]_{t} \\
\Sigma z_{X}[X]_{p}=\left[\mathrm{Cl}^{-}\right]_{t}+2\left[\mathrm{SO}_{4}^{2-}\right]_{t}+\left[\mathrm{NO}_{3}^{-}\right]_{t} \equiv \text { pollution }
\end{gathered}
$$

where $z_{X}$ is the ionic charge of $X$. The deviations in the charge balances for bicarbonate (ErrR) and pollution (ErrP) are calculated by

$$
\begin{aligned}
& \operatorname{Err} R(\%)=\frac{\Sigma z_{X}[X]_{r}-\left[\mathrm{HCO}_{3}^{-}\right]_{t}}{\Sigma z_{X}[X]_{r}+\left[\mathrm{HCO}_{3}^{-}\right]_{t}} \times 100 \\
& \operatorname{Err} P(\%)=\frac{\Sigma z_{X}[X]_{p}-\text { pollution }}{\Sigma z_{X}[X]_{p}+\text { pollution }} \times 100
\end{aligned}
$$

Geological criteria may be used. An important clue is that we write each set of weathering reactions with a specific petrological area in mind. In the end the samples related to that set of weathering reactions must have a spatial relation with the petrology and mineralogy of that area.

Acknowledgments. The first author received an ERASMUS scholarship from the European Community upon the recommendation of M. Portugal Ferreira of the Geology Department of the Universidade de Coimbra. He also thanks João Brandão of the Chemistry Department of Coimbra University for his advice. R. D. Gill of the Mathematical Department of Utrecht University gave helpful comments on the RST algorithm presented in this paper. We also thank two anonymous referees and the associate editor for their constructive remarks and suggestions on an earlier version of this paper. Contribution 960501 of the Netherlands Research School of Sedimentary Geology.

\section{References}

Costa, C. V., L. G. Pereira, M. Portugal Ferreira, and J. M. Santos Oliveira, Distribuição de oligoelementes nas rochas e solos da região do Fundão, Memórias e Notícias, Mus. e Lab. Mineral. e Geol. da Univ. de Coimbra, 71, 1-37, 1971.

Davis, J. C., Statistics and Data Analysis in Geology, 646 pp., John Wiley, New York, 1986.

Deer, W. A., R. A. Howie, and J. Zussmann, Rock-Forming Minerals, vol. 1-5, Longmans, Green, Toronto, Ont., 1962.

Drever, J. I., The Geochemistry of Natural Waters, 437 pp., PrenticeHall, Englewood Cliffs, N. J., 1988.

Everitt, B., Cluster Analysis, 122 pp., Heinemann, London, 1977.

Garrels, R. M., Genesis of some ground waters from igneous rocks, in Researches in Geochemistry, vol. 2, edited by P. H. Abelson, pp. 405-420, John Wiley, New York, 1967.

Garrels, R. M., and F. T. Mackenzie, Origin of the chemical compositions of some springs and lakes, in Equilibrium Concepts in Natural Water Systems, Adv. Chem. Ser., vol. 67, edited by R. F. Gould, pp. 222-242, Am. Chem. Soc., Washington, D. C., 1967.

Hartigan, J., Clustering Algorithms, 351 pp., Wiley-Interscience, New York, 1975.
Kaufman, L., and P. J. Rousseeuw, Finding Groups in Data, 342 pp., John Wiley, New York, 1990.

Pačes, T., Chemical characteristics and equilibration in natural waterfelsic rock- $\mathrm{CO}_{2}$ system, Geochim. Cosmochim. Acta, 36, 217-240, 1972.

Pačes, T., Steady-state kinetics and equilibrium between ground water and granitic rock, Geochim. Cosmochim. Acta, 37, 2641-2663, 1973.

Portugal Ferreira, M., A magmatic arc in the Iberian Segment of the Hercynian chain, I, The northwest-southeastlineament between Oporto (Portugal) and Zarza la Major (Spain), Memórias e Notícias, Mus. e Lab. Mineral. e Geol. da Univ. de Coimbra, 94, 31-50, 1982. Portugal Ferreira, M., E. Ivo Alves, and C. A. Regêncio Macedo, A zonalidade de um plutonito: estruturas condicionantes e idades de evolução (Plutonito do Fundão, Portugal central), Memórias e Notícias, Mus. e Lab. Mineral. e Geol. da Univ. de Coimbra, 99, 167186, 1985.

Press, W. H., B. P. Flannery, S. A. Teukolsky, and W. T. Vetterling, Numerical Recipes in Pascal, 759 pp., Cambridge Univ. Press, New York, 1989

Sverdrup, H. V., and P. Warfvinge, On the geochemistry of chemical weathering, in Chemical Weathering Under Field Conditions, Rep. For. Ecol. For. Soil 63, edited by K. Rosén, pp. 79-119, Swed. Univ. Agric. Sci., Uppsala, 1991.

Tardy, Y., Characterization of the principle weathering types by the geochemistry of waters from some European and African crystalline massifs, Chem. Geol., 7, 253-271, 1971.

Tardy, Y., G. Bocquier, H. Paquet, and G. Millot, Formation of clay from granite and its distribution in relation to climate and topography, Geoderma, 10, 271-284, 1973.

Van der Weijden, C. H., M. G. Oosterom, J. Bril, C. G. Walen, S. P. Vriend, and B. W. Zuurdeeg, Geochemical controls of transport and deposition of uranium from solution: Case study: Fundão, Portugal, Tech. Rep., Inst. of Earth Sci., Dep. of Geochem., Utrecht Univ., Utrecht, Netherlands, 1983.

Velbel, M. A.. Geochemical mass balances and weathering rates in forested watersheds of the southern Blue Ridge, Am. J. Sci., 285, 904-930, 1985a.

Velbel, M. A., Hydrogeochemical constraints on mass balances in forested watersheds of the southern Appalachians, in The Chemistry of Weathering, NATO ASI Ser., edited by J. I. Drever, pp. 231-247, D. Reidel, Norwell, Mass., 1985b.

Velbel, M. A., Weathering of hornblende to ferruginous products by a dissolution-reprecipitation mechanism: Petrography and stoichiometry, Clays Clay Miner., 37, 515-524, 1989.

Velbel, M. A., Geochemical mass balances and weathering rates in forested watersheds of the southern Blue Ridge, III, Cation budgets and the weathering rate of amphibole, Am. J. Sci., 292, 58-78, 1992.

F. Pacheco, Secção de Geologia, Universidade de Trás-os-Montes e Alto Douro, 5000 Vila Real, Portugal. (e-mail: fpacheco@utad.pt)

C. H. Van der Weijden, Department of Geochemistry, Institute of Earth Sciences, Utrecht University, P.O. Box 80.021, 3508 TA Utrecht, Netherlands. (e-mail: chvdw@earth.ruu.nl)

(Received January 15, 1996; revised May 28, 1996; accepted May 28, 1996.) 